\title{
Avaliação de estratégias para representação e análise do planejamento e controle de obras utilizando modelos BIM 4D
}

\author{
Evaluation of strategies for representation and analysis \\ of construction planning and control using 4D BIM models
}

\section{Douglas Malheiro de Brito Emerson de Andrade Marques Ferreira}

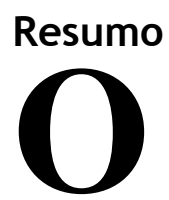

objetivo deste artigo é avaliar estratégias para representação e análise do planejamento e controle de obras utilizando Modelos BIM 4D, segundo a visão de profissionais da indústria da construção civil brasileira. A pesquisa envolveu revisão bibliográfica sobre o tema, estudo de caso em um empreendimento com utilização do modelo para planejamento e controle da obra e o desenvolvimento e aplicação de questionário digital para avaliação das potencialidades e estratégias pelos profissionais do setor. O questionário da pesquisa abordou estratégias para representação e análise utilizando cores para diferenciação das atividades internas, alternativas de monitoramento do avanço físico através de simulação dos cronogramas Planejado e Realizado, e visualização deles em tela dividida, além de avaliação sobre adoção de modelos 4D. Os resultados obtidos indicam os graus de importância e aplicabilidade dos aspectos analisados na visão geral dos participantes e estratificados por nível de conhecimento sobre BIM, formação profissional, área de atuação e grau acadêmico.

Palavras-chave: Modelagem da informação da construção. Modelos BIM 4D. Estratégias para representação e análise de projetos. Planejamento. Controle.

\begin{abstract}
The aim of this study is to evaluate strategies for the representation and analysis of construction planning and control using 4D BIM Models, based on the views of Brazilian construction industry professionals. The study involved a literature review, a case study in a construction project using the planning and control model and the development and application of a digital questionnaire to evaluate the potentials and strategies applied to the industry's professionals. The survey questionnaire included questions on strategies for representation and analysis using colours to differentiate internal activities, alternatives to monitor the physical advance through Planned $x$ Realized schedules simulation and their visualization on split screens, as well as an evaluation about the adoption of $4 D$ Models. The results obtained indicate the degrees of importance and applicability of the analysed aspects from the point of view of the participants, who were view and stratified according to their knowledge level about BIM, academic degree, practice area and educational level.
\end{abstract}

Recebido em 15/03/15 Aceito em 15/08/15

Douglas Malheiro de Brito Salvador - BA - Brasil

Emerson de Andrade Marques Ferreira

Universidade Federal da Bahia
Keywords: Building Information Modeling. 4D BIM models. Strategies for project representation and analysis. Planning. Control. 


\section{Introdução}

Building Information Modeling (BIM), também conhecido como Modelagem da Informação da Construção, consiste em um processo melhorado para planejar, projetar, construir, usar e manter uma edificação durante todo seu ciclo de vida, a partir de um modelo de informação normalizado que contém todas as informações necessárias aos interessados (UNITED..., 2008).

Uma das dificuldades enfrentadas pela indústria da construção é a dificuldade em visualizar corretamente o planejamento da obra no espaço, gerando cronogramas de interpretação abstrata para os usuários devido ao grande número de atividades e precedências. Modelos 4D conectam intimamente aspectos espaciais e temporais do projeto, melhorando a confiabilidade dos cronogramas e minimizando problemas de comunicação (KOO; FISCHER, 2000; HARTMANN; GAO; FISCHER, 2008).

Existem alguns entraves para a adoção de modelos 4D em maior escala segundo Koo e Fischer (2000) e Russell, Chiu e Korde (2009), tais como a necessidade de mecanismos para visualização do avanço das atividades internas, a existência de limitações na detecção de conflitos de espaço e tempo pelos usuários e a falta de análise de algumas informações do modelo (tamanho das equipes, equipamentos, espaços de trabalho, zonas de segurança).

Enquanto interações com modelos 3D são amplamente discutidas em pesquisas, o uso de modelos 4D é menos abordado, existindo uma necessidade urgente de explorar e avaliar esses modelos. Poucas pesquisas avaliam a importância e aplicabilidade de estratégias para representação e análise da modelagem 4D validadas por profissionais do setor. Um estudo conduzido por Mahalingam, Kashyap e Mahajan (2010) identificou potencialidades na fase de planejamento do projeto para comunicar opções de métodos construtivos e na fase construtiva para análises de execução, detecção de interferências e monitoramento do avanço do projeto. Outro desafio para a disseminação dos modelos 4D é a falta de padrões de visualização acordados para representação das atividades e elementos da construção. Castronovo et al. (2014) reuniram um conjunto de diretrizes para interação, visualização e representação.

A indústria da construção civil do Brasil está entre as maiores do mundo, representando $2 \%$ da indústria global, reforçando o impacto significativo a se obter com a adoção de conceitos e ferramentas do BIM (KASSEM, 2014). Dessa forma, este trabalho tem como objetivo avaliar estratégias para representação e análise do planejamento e controle de obras utilizando modelos BIM 4D, segundo a visão de profissionais da indústria da construção civil brasileira.

\section{Planejamento e controle de obras}

Mattos (2010) considera que o processo de planejamento e controle de uma obra possui influência decisiva no desempenho da produção já que deficiências nesse processo estão entre as causas mais importantes de baixas produtividades, elevados desperdícios e baixa qualidade dos produtos gerados. Além disso, o planejamento e o controle se relacionam de uma maneira complementar, sendo condicionantes para a obtenção dos resultados esperados de custo, prazo e qualidade de um projeto.

O controle da produção é, para Limmer (1997), conhecer e corrigir os desvios que venham a ocorrer em relação ao planejado e ainda avaliar continuamente a qualidade do que foi planejado. $\mathrm{O}$ controle é a finalização do ciclo lógico de gerenciamento de um projeto, através da aferição do executado, comparando-o com o planejado, buscando determinar o avanço, detectar desvios e definir correções em uma retroalimentação contínua do processo.

Entre as peculiaridades da construção civil estão a fragmentação, o uso intensivo da mão de obra, o caráter nômade das obras, além da grande quantidade de materiais e intervenientes, o que a diferencia das demais indústrias e, consequentemente, exige o desenvolvimento de estratégias de produção adaptadas a essa realidade (FORMOSO; INO, 2003).

As principais técnicas de planejamento utilizam cronogramas, diagramas de rede e linhas de balanço, sendo os primeiros métodos os mais disseminados no gerenciamento de obras, ainda que encontrem fortes limitações nas atividades que possuem muitas interligações ou provoquem mudanças nos caminhos críticos. Por outro lado, a linha de balanço encontra dificuldades com atividades discretas ou não repetitivas, comuns em alguns tipos de obras, o que pode impedir o desenvolvimento do planejamento até que a sincronização dessas atividades esteja compatível com as demais (LIMMER, 1997).

Laufer e Tucker (1987) dividem o planejamento em três níveis hierárquicos em função do nível de detalhamento e da proximidade da execução do 
plano: estratégico, tático e operacional. O estratégico ou de longo prazo é o mais geral e duradouro, estabelecendo prazos, ciclos e processos. O tático ou de médio prazo vincula o plano estratégico com o operacional, buscando remover as restrições para a realização dos serviços, estabelecendo programação, sequência de execução e os recursos que serão necessários. O planejamento de curto prazo ou operacional tem o maior nível de detalhamento, distribuindo os pacotes de trabalho para as equipes e exigindo um efetivo controle da programação.

Segundo eles, a não identificação das necessidades dos usuários, em cada fase, gera falhas na implementação de sistemas computacionais de planejamento, inadequados ao ambiente organizacional, produzindo informações irrelevantes ou desnecessárias, que dificultam a manutenção do plano atualizado e a integração necessária entre os níveis de planejamento.

\section{Modelagem BIM 4D}

A Modelagem da Informação da Construção compreende muitas das funções necessárias para representar todo o ciclo de vida de um projeto, fornecendo a base para uma nova forma de projetar, construir, gerenciar e utilizar um empreendimento. Quando adotado corretamente, contribui para um processo de concepção e construção mais integrado, o que gera empreendimentos de maior qualidade a custos e durações menores (EASTMAN et al., 2011).

Koo e Fischer (2000) consideram que os cronogramas tradicionais não fornecem informações suficientes referentes ao contexto espacial e a complexidade dos componentes de um projeto, resultando em uma representação abstrata do planejamento. Modelos 4D permitem aos planejadores algumas potencialidades como a visualização do processo de construção, maior compreensão do cronograma, detecção de erros e problemas potenciais antes da execução. Eastman et al. (2011) relatam também outros benefícios relacionados à melhoria da comunicação, gerenciamento logístico facilitado, comparação de planos de execução e controle do avanço físico da construção.

A indústria da construção civil precisa compreender melhor e de forma mais ampla sobre como utilizar modelos BIM para o gerenciamento de projetos (HARTMANN; GAO; FISCHER, 2008). Biotto, Formoso e Isatto (2012) utilizaram modelos 4D para atividades de planejamento e controle, relatando como principais benefícios a visualização de erros de sequenciamento, conflitos entre equipamentos e restrições físicas do canteiro, o apoio na conformação dos fluxos de trabalho e a definição logística de equipamentos, demonstrando a capacidade das informações contidas nos modelos 4D para apoiar a tomada de decisões gerenciais. Biotto, Formoso e Isatto (2013) apresentaram um método de gerenciamento da produção com utilização da modelagem BIM 4D, que abrange as diversas etapas do processo de planejamento e controle, e contribui para auxiliar a implantação em novos empreendimentos.

Outros trabalhos também têm discutido o tema e apresentado as aplicações desenvolvidas, a exemplo do sistema de verificação de conflitos de espaço de trabalho entre atividades do cronograma (MOON; DAWOOD; KANG, 2014), uso do BIM integrado ao planejamento e controle de uma obra para tomar decisões, instruir subcontratados e tornar o processo mais enxuto (SCHEER et al., 2014) e simulação com prototipagem virtual para escolher a alternativa de construção ideal (LI et al., 2012), entre outros.

\section{Estratégias para representação e análise}

A capacidade de visualização das informações de planejamento e controle nos modelos BIM 4D é um dos aspectos fundamentais para uma implantação bem-sucedida. A habilidade de comunicar informações sobre o avanço e discrepâncias em relação ao planejado com eficácia é estratégica para o gerenciamento de projetos, pois possibilita a tomada de ações corretivas em tempo hábil. Golparvar-Fard et al. (2009) desenvolveram uma técnica de monitoramento do avanço a partir da visualização do modelo 4D sobreposto a fotografias do avanço real.

Nos modelos 4D, a representação do avanço das atividades ao longo do tempo utiliza cores, as quais são essenciais para o melhor entendimento e a realização de análises gerenciais. Chang, Kang e Chen (2009) e Chen et al. (2013) notaram que os planejadores escolhem os esquemas de cores para representar os estados construtivos dos modelos a partir de preferências pessoais, o que pode causar dificuldades aos usuários. Em seus trabalhos foram desenvolvidos procedimentos sistemáticos para seleção e avaliação de esquemas de cores ideais.

A aplicabilidade da modelagem 4D é limitada quando o acesso visual às atividades que ocorrem internamente é restrito. Russell et al. (2009) e Golparvar-Fard et al. (2009) consideram essencial para a visualização do avanço de um empreendimento enxergar o progresso das atividades internas. Alguns mecanismos foram desenvolvidos para o combate dessas dificuldades, 
entre os quais ocultar os níveis acima dos locais onde estão acontecendo atividades internas, ajustar a transparência de alguns elementos para facilitar a visualização, controlar a velocidade e inserir pausas na simulação do cronograma, e exibir ao mesmo tempo duas simulações em tela dividida para avaliar métodos construtivos ou confrontar os cronogramas Planejado e Realizado (RUSSELL et al., 2009; SONG; YANG; KIM, 2012). Entretanto, esses trabalhos não utilizaram diferenciação de cores para representar as atividades internas como forma de melhoria da visualização.

Representações visuais interativas auxiliam na análise de informações gerenciais e, consequentemente, na tomada de decisão (RUSSELL; CHIU; KORDE, 2009). Embora interações com modelos 3D sejam amplamente discutidas na literatura, o uso 4D colaborativo é menos abordado. Em outro trabalho, Boton, Halin e Kubicki (2014) propõem algumas variáveis que devem ser consideradas para a simulação 4D colaborativa, como o tipo de conteúdo a ser manipulado, características do modelo e peculiaridades dos usuários. $\mathrm{O}$ processo de coordenação 4D foca nas interdependências operacionais, visualizações detalhadas, detecção de conflitos e desenvolvimento de estratégias de contenção, a fim de reforçar o nível de plena atenção, a capacidade de detectar potenciais erros operacionais e tomar ações corretivas em relação ao processo de coordenação tradicional (OLDE SCHOLTENHUIS; HARTMANN; DORÉE, 2014).

A proliferação de qualquer nova tecnologia requer padrões acordados para sua utilização. Um dos desafios para esse caso é a necessidade de definir padrões de visualização para representação dos elementos da construção. Castronovo et al. (2014) perceberam que a visualização de elementos 3D em simulações 4D pode ser influenciada por propriedades gráficas como cor, iluminação ou transparência e pelo nível de interação. Entre as diretrizes para visualização e representação reunidas na pesquisa, destacam-se o uso de legendas com as cores da representação, diferenciação de luminosidade para distinção de elementos e vários níveis de transparência para definir o estado das atividades.

\section{Pesquisas sobre utilização do BIM}

A Modelagem da Informação da Construção está em processo de disseminação no mundo, mas ainda existem diferenças significativas entre as experiências vivenciadas pelas empresas de construção e os benefícios da utilização do BIM em diversas regiões (BERNSTEIN et al., 2014).
Nesse mesmo estudo, o qual investigou o uso do BIM em mercados globais de 10 países de diversos continentes, os sete principais benefícios percebidos pelos contratantes foram redução de erros e omissões (41\%), colaboração entre proprietários e firmas de projeto $(35 \%)$, melhora da imagem organizacional $(32 \%)$, redução do retrabalho $(31 \%)$, redução de custos $(23 \%)$, melhor controle de custos $(21 \%)$ e redução da duração geral do projeto (19\%)

O potencial de aplicação e os benefícios obtidos com o BIM são amplamente aceitos pelos profissionais da construção civil, entretanto os fatores que influenciam sua adoção não estão totalmente esclarecidos. Lee, Yu e Jeong (2013) propuseram um modelo de aceitação do BIM composto de um conjunto de fatores que influenciam sua adoção pelas organizações e entrevistaram profissionais da construção civil da Coreia do Sul que já utilizavam o BIM em suas empresas. Os resultados observados indicaram que a aceitação e a adoção bem-sucedida dependem da disposição organizacional e do envolvimento dos profissionais em um sistema de cooperação para uso das ferramentas. Xu, Feng e Li (2014) realizaram pesquisa com a indústria da construção chinesa e perceberam que dimensões organizacionais, tecnológicas e de atitude (vontade e interesse) afetam indiretamente a adoção do BIM, sendo a utilidade percebida e a facilidade de uso determinantes para a propagação em larga escala.

A partir de uma investigação envolvendo 106 projetos públicos e privados, com diferentes tipologias e custos, localizados em diversas regiões da China, Cao et al. (2015) apresentaram uma visão geral das práticas atuais do BIM na indústria da construção civil chinesa. Os pesquisadores identificaram limitações na profundidade da aplicação do BIM na China, restringindo-se principalmente a ferramentas de visualização. Ainda que grande parte dos projetos pesquisados tentasse realizar diversas aplicações, a análise dos resultados indicou que o uso do BIM em 31,13\% deles era restrito a uma única etapa do projeto.

Eadie et al. (2013) conduziram estudo sobre os impactos, aplicações e identificação dos beneficiários do BIM no Reino Unido durante o ciclo de vida dos empreendimentos. Os participantes consideraram como principais impactos a colaboração, o entendimento como um processo (e não como uma tecnologia) e a redução de desperdícios (materiais, recursos e custos). Em relação às aplicações, a mais frequente ocorre nas fases anteriores à construção, como a de projeto, seguida pela fase construtiva com $34,67 \%$ dos participantes utilizando regularmente e pela fase de 
operação com apenas $8,82 \%$. Os clientes foram considerados como os que mais se beneficiam financeiramente, seguidos pelos gestores de manutenção e operação, vendedores de softwares e contratantes principais.

Outras pesquisas encontradas sobre modelos 4D relativas a seu uso para planejamento e controle de obras baseadas na visão de profissionais do setor abordam modelos CAD 4D, os quais, apesar de não possuírem algumas características do BIM, como a automatização e a capacidade de reorganização, possibilitam sua visualização no espaço e no tempo. Em um desses estudos foi realizada uma avaliação de sua usabilidade por 63 participantes da indústria da construção da Índia, incluindo a alta gerência, gerência operacional e trabalhadores de obras (MAHALINGAM; KASHYAP; MAHAJAN, 2010).

Para realizar a pesquisa com o setor de construção indiano, Mahalingam, Kashyap e Mahajan (2010) elaboraram um questionário utilizando uma Escala Likert de 5 níveis, variando entre 1 , sem usabilidade, até 5, alto grau de usabilidade. Entre as hipóteses avaliadas, a usabilidade dos modelos 4D obteve a maior média na fase de concepção do projeto $(4,40)$ para comunicação dos planos construtivos, seguida pela fase construtiva $(4,03)$ para análises da execução, detecção de conflitos e monitoramento, e pela fase de detalhamento do projeto $(3,88)$ para comunicação entre projetistas e resolução de incompatibilidades. O referido estudo considera que a modelagem $4 \mathrm{D}$ pode não se propagar na construção civil até que esteja realmente integrada com os processos de planejamento existentes e que as ferramentas de análise para acelerar a tomada de decisão estejam automatizadas.

O uso do BIM no Brasil é mais recente e restrito em relação a outros países, o que torna necessária a realização de mais estudos sobre esse tema. Bernstein et al. (2014) constataram que dos contratantes brasileiros que participaram da pesquisa $70 \%$ possuíam no máximo 2 anos de utilização, índice muito acima dos verificados em países da Europa, América do Norte, Ásia e Oceania. Além disso, apenas $24 \%$ das organizações brasileiras que já utilizam o BIM adotam as técnicas em mais de $30 \%$ de seus projetos, índice inferior à média mundial.

Com relação às atividades relacionadas ao BIM tidas como uma das três mais relevantes pelos contratantes na fase anterior à construção a integração do modelo com o cronograma (4D) é citada por $72 \%$ dos participantes brasileiros, o maior percentual entre os países analisados. O monitoramento do avanço foi considerado como uma das três atividades mais relevantes da fase construtiva por $32 \%$ dos brasileiros, um pouco abaixo da média mundial.

Amorim (2014) enviou questionário para 282 associações e escritórios de arquitetura, obtendo 40 respostas $(14,18 \%$ do total) e identificou que $20 \%$ dessas organizações não desenvolviam nenhuma ação sobre BIM (treinamentos, eventos, palestras e documentação). Em relação às demais organizações, $28 \%$ não tinham grupo de pesquisa nesse tema, 44\% tinham grupo formado entre 1 e 3 anos, e 28\% tinham há mais de 3 anos. Quanto à importância dada pelo setor de projeto ao BIM para melhoria de desempenho da construção civil, $70 \%$ optaram por nível 4 ou 5 (escala Likert de 1 a $5)$, enquanto o menor nível considerado foi 2 (10\% das respostas), demonstrando o alto nível de importância (média 4,00) dado pelos participantes.

Amorim (2014) também avaliou a opinião da cadeia de suprimentos da construção civil brasileira. Mais da metade das empresas (54\%) nunca desenvolveu nenhuma ação sobre BIM, enquanto $38 \%$ das que já desenvolveram elaboraram bibliotecas de produtos virtuais. $\mathrm{O}$ nível de importância do BIM para melhoria do desempenho do setor obteve 4 ou 5 para $57 \%$ dos participantes, e 3 para $17 \%$, índices mais baixos que os anteriores, com os profissionais de projeto, enquanto $13 \%$ não sabiam ou não conheciam. Em relação à importância da utilização do BIM para a melhoria de desempenho na logística de materiais para construção, 39\% optaram por 4 ou $5,17 \%$ avaliaram a importância como nível 3, e $26 \%$ não sabiam ou não conheciam, indicando o desconhecimento do setor sobre o potencial do BIM em gerar ganhos logísticos.

\section{Método de pesquisa}

Este trabalho foi desenvolvido a partir da realização das seguintes etapas: revisão bibliográfica sobre planejamento e controle de obras, modelagem BIM 4D; estudo de caso em um empreendimento com utilização do modelo para o planejamento e controle da obra; desenvolvimento e aplicação de questionário digital para avaliação das potencialidades e estratégias identificadas e utilizadas durante o estudo de caso; análise dos dados da amostra dos participantes da pesquisa; e indicação das estratégias mais adequadas para representação e análise do planejamento e controle de obras utilizando modelos BIM 4D, segundo a visão dos profissionais da construção civil brasileira. A Figura 1 demonstra o delineamento da pesquisa e a sequência de métodos utilizados. 
Figura 1 - Delineamento do estudo

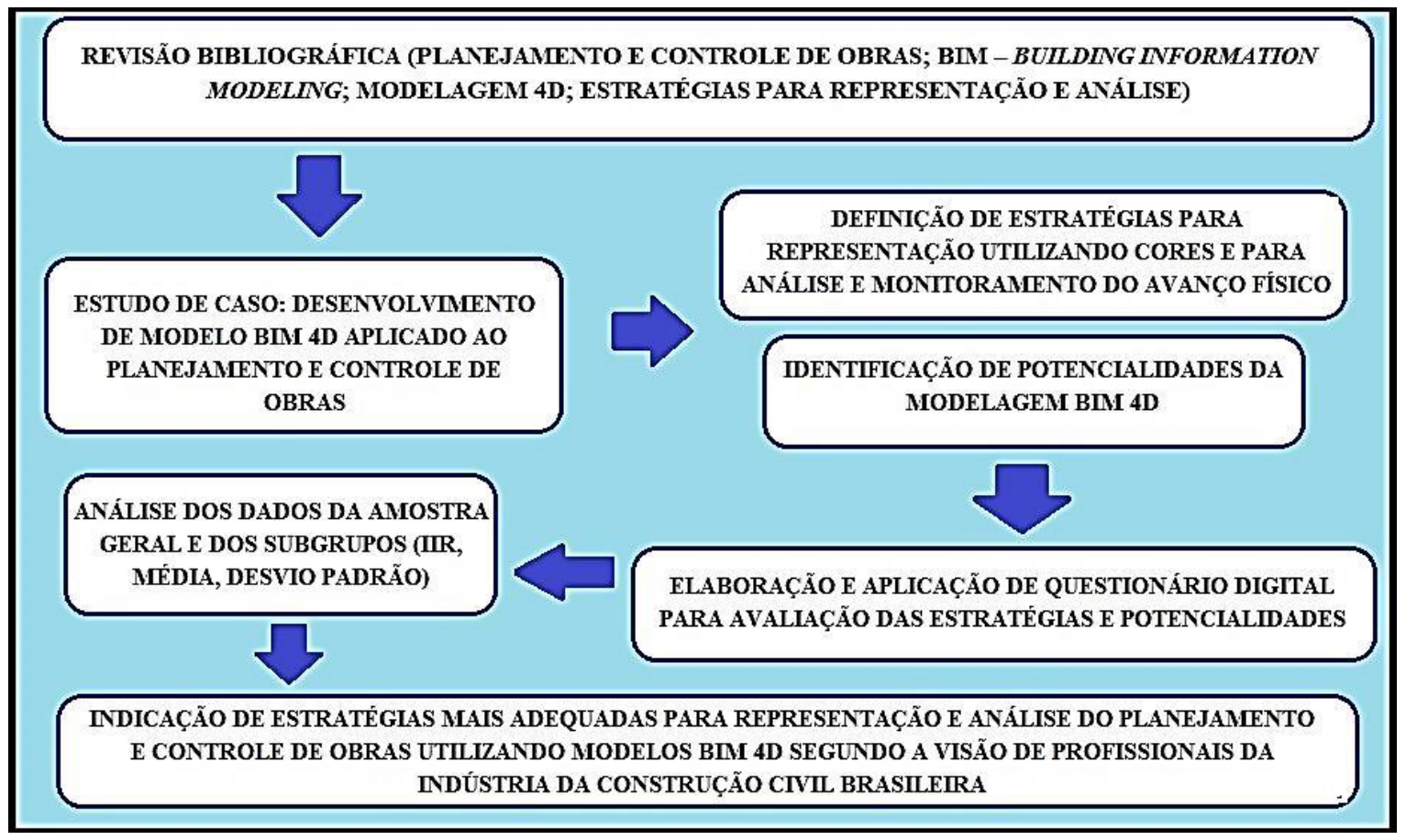

O principal objetivo deste estudo é avaliar estratégias para representação e análise do planejamento e controle de obras utilizando modelos BIM 4D, com base na visão de profissionais da indústria da construção civil brasileira. A definição das estratégias avaliadas considerou a revisão bibliográfica sobre o tema e um estudo de caso, em que foi desenvolvido um modelo BIM 4D de um empreendimento para simulação do planejamento, acompanhamento do avanço físico e identificação de suas potencialidades.

O estudo de caso foi realizado em uma construção residencial horizontal com 6 módulos de 2 andares, totalizando 64 unidades e com prazo de execução planejado em 18 meses, localizada próximo da cidade de Salvador, BA, na região Nordeste do Brasil, pertencente a uma construtora iniciante na utilização do BIM em seus projetos que desenvolvia pesquisas em conjunto com universidades. O desenvolvimento do modelo BIM 4D utilizado necessitou, inicialmente, de uma revisão do planejamento da obra no Microsoft Project $^{\circledR}$, identificando as atividades que deveriam ser representadas, com o nível de detalhe proposto, para a aplicação e a vinculação desse cronograma com os projetos BIM 3D através do software Navisworks ${ }^{\circledR}$, que realiza essa integração.

A coleta de dados e o acompanhamento da obra ocorreram por meio de visitas de campo, quando foram realizadas reuniões com o gerente do empreendimento para apresentação e discussão das informações fornecidas pelo modelo, relativas ao andamento da obra, visando à realização de possíveis ajustes quando necessário e à identificação das potencialidades e limitações da modelagem 4D.

Após essa etapa foi desenvolvido questionário no Google Docs para avaliar o grau de importância e aplicabilidade de estratégias para representação e análise do planejamento e controle de obras utilizando modelos BIM 4D, através de uma Escala Likert com cinco níveis $(1$ - Muito Baixo(a); 2 - Baixo(a); 3 - Médio(a); 4 - Alto(a); 5 - Muito Alto(a)). A escolha das variáveis grau de importância e aplicabilidade para avaliar as questões se baseou na necessidade de saber o que era considerado relevante pelos participantes e, ao mesmo tempo, o quão prático e aplicável eram essas questões. Park et al. (2011) também utilizaram essas variáveis para avaliar 35 áreas de aplicação de CAD 3D/4D nas fases de um empreendimento.

O questionário foi enviado por e-mail para profissionais de diversos setores da indústria da construção brasileira entre alunos de pósgraduação, empresas e universidades com atuação conhecida pelos pesquisadores relacionada ao BIM e à gestão da construção. A pesquisa foi respondida por 66 profissionais, incluindo 19 arquitetos e 46 engenheiros, e foi enviada para uma amostra total de 215 pessoas. O questionário foi enviado uma segunda vez para aqueles profissionais que não responderam inicialmente à 
pesquisa, relembrando-os a respeito do primeiro email, tendo sido solicitado a alguns profissionais de universidades e empresas que replicassem o email para outros com atuação relacionada ao BIM e à gestão da construção.

Com base nas informações dos participantes, a divisão da amostra pelas principais áreas de atuação foi a seguinte: construção $(28,8 \%)$, projeto $(27,3 \%)$, gerenciamento $(16,7 \%)$, e pesquisa e ensino $(16,7 \%)$. Com relação ao grau acadêmico, $31,8 \%$ possuem apenas graduação, enquanto $68,2 \%$ possuem pós-graduação, incluindo MBA, mestrado, doutorado ou pós-doutorado. Considerando o nível de conhecimento e uso do BIM, 43,9\% dos participantes não conhecem ou conhecem mas nunca o utilizaram; já os demais conhecem e utilizam ou utilizaram BIM em três níveis: pouco $(15,2 \%)$, medianamente $(21,2 \%)$ e muito $(19,7 \%)$

O questionário foi estruturado da seguinte forma: informações sobre o perfil dos participantes (nome, faixa de idade, sexo, estado onde atua profissionalmente, formação, grau acadêmico, área de atuação profissional, nível de conhecimento e uso do BIM), avaliações a respeito do grau de importância e aplicabilidade de potencialidades e estratégias para representação e análise e uma avaliação final sobre a adoção da modelagem 4D.

Quando necessário, as questões da pesquisa foram acompanhadas de vídeos extraídos do modelo 4D, para melhor compreensão dos participantes com relação ao que estava sendo avaliado. Esses vídeos eram de curta duração para garantir que o tempo total demandado pelos participantes para resposta do questionário não ultrapassasse $10 \mathrm{~min}$, sendo informado que o modelo 4D possui flexibilidade para simulações com variadas velocidades, durações, vistas, entre outras características escolhidas pelo usuário.

A primeira parte era precedida por um vídeo de 45 $\mathrm{s}$ com a simulação do planejamento do empreendimento, incluindo elementos de canteiro, como instalações provisórias, estoques e equipamentos, sendo avaliadas seis potencialidades relatadas na literatura e identificadas no estudo de caso.

A segunda parte do questionário avaliou as estratégias para representação e análise desenvolvidas no estudo de caso, compreendendo o uso de cores para diferenciação das atividades internas do modelo e alternativas de monitoramento do avanço físico da obra através da simulação dos cronogramas Planejado e Realizado, e visualização desses cronogramas em tela dividida, em datas específicas. Para a avaliação do uso de cores foram apresentados aos participantes dois vídeos curtos, de $30 \mathrm{~s}$, o primeiro deles com a simulação do planejamento de um módulo específico da obra com o sequenciamento das atividades internas e externas representadas por cor única, e o segundo vídeo com a mesma simulação utilizando cores para diferenciação das atividades internas, acompanhada de uma legenda com a definição das cores para cada uma delas.

A avaliação das alternativas de monitoramento do avanço físico também foi precedida por dois vídeos com duração de $30 \mathrm{~s}$ cada, sendo o primeiro com a simulação de parte dos cronogramas Planejado e Realizado da obra, sem a divisão de tela e acompanhado de uma legenda com a diferenciação de cores para representação dos estados das atividades (adiantadas, dentro do previsto, atrasadas), enquanto o outro vídeo com uma exibição dos cronogramas Planejado e Realizado em tela dividida em cinco datas específicas.

A última parte do questionário consistiu em uma avaliação sobre a adoção da modelagem 4D ao planejamento e controle de obras. Todas as questões eram de preenchimento obrigatório com a restrição da marcação de um único nível da Escala Likert e possuíam espaço para envio de comentários opcionais por parte dos participantes.

O questionário teve sua consistência interna validada por meio do coeficiente alfa de Cronbach (HORA; MONTEIRO; ARICA, 2010), o qual varia entre zero e um, sendo aceitável na literatura com valores acima de 0,70 . O cálculo de seu valor para todos os itens do questionário resultou em 0,892, indicando a boa confiabilidade do instrumento utilizado.

A análise dos dados do questionário utilizou o Índice de Importância Relativa (IIR), o qual vem sendo empregado para hierarquizar quesitos avaliados em uma grandeza entre 0 e 1 em algumas pesquisas do setor, tais como Sousa (2008), Eadie et al. (2013) e Muhwezi, Acai e Otim (2014), para a avaliação das seis potencialidades da modelagem 4D, visando estabelecer um ranking entre elas, sendo o IIR definido pela Equação 1:

$$
(I I R)=\frac{\sum P}{A \times N}
$$

$0 \leq \mathrm{IIR} \leq 1$

Onde:

$\mathrm{P}=$ é o peso dado para cada elemento pelos participantes, variando entre 1 e 5 nessa Escala Likert, em que 1 é o grau menos significativo, e 5 é o grau mais significativo; 
$\mathrm{A}=$ é o maior peso, que representa o grau mais significativo, neste caso de valor 5; e

$\mathrm{N}=$ é o total da amostra (66 participantes).

Esta pesquisa também utilizou as técnicas estatísticas: cálculo do coeficiente de correlação de Pearson, entre os itens do questionário com relação ao grau de importância e aplicabilidade de cada um deles e determinação da média, desvio padrão e intervalo de significância com alfa de 0,05 , correspondente a um intervalo de confiança (IC) de $95 \%$ para cada questão avaliada pela amostra geral, além dos subgrupos da amostra divididos ou combinados por especificidades, relacionadas ao nível de conhecimento e utilização do BIM, formação profissional, área de atuação, grau acadêmico, entre outras.

\section{Desenvolvimento do modelo BIM 4D aplicado ao planejamento e controle de obras}

O processo de desenvolvimento do modelo BIM 4D envolveu a revisão do planejamento inicial da obra no Microsoft Project ${ }^{\circledR}$, definindo as atividades que seriam representadas e, após isso, a exportação dos projetos 3D já modelados no Revit $^{\circledR}$ e a abertura deles no Navisworks ${ }^{\circledR}$, junto com o cronograma revisado, quando foi feita a associação das atividades do cronograma com os elementos correspondentes do projeto, gerando o modelo 4D.

\section{Estratégias para representação utilizando cores}

Após o desenvolvimento do modelo, foi possível simular o cronograma da obra para realizar análises do planejamento, incluindo plano de ataque, sequência de execução e leiaute do canteiro de obras. Durante a simulação, os elementos na cor azul representam as atividades que estão acontecendo ao longo do tempo. A escolha da cor azul ocorreu por ela pertencer à escala de cores frias, adequadas para indicar condições seguras e estáveis, tais como o que foi planejado, e a não utilização de efeitos de transparência teve como objetivo não confundir os usuários, conforme literatura (CHANG; KANG; CHEN, 2009).

Nas simulações para os engenheiros da obra, foram identificadas algumas dificuldades para visualização eficiente do modelo, quando estavam ocorrendo muitas atividades internas e externas ao mesmo tempo. Constatou-se que existe a tendência de que outros elementos do modelo, como a fachada, cobertura e estrutura, encubram as atividades internas, principalmente quando todas as atividades são representadas por uma única cor, assim como na Figura 2, que representa as atividades internas e externas que ocorrem com a cor azul.

A partir das dificuldades encontradas inicialmente, foi desenvolvido um modelo 4D utilizando cores definidas para representar cada uma das sete atividades internas. Além disso, essa nova representação deveria aparecer externamente na fachada de cada pavimento, onde cada atividade interna poderia acontecer para possibilitar a visualização pelos usuários e, ao mesmo tempo, não interferir numa possível atividade externa que acontecesse nesse mesmo local.

Figura 2 - Atividades internas e externas representadas por uma única cor

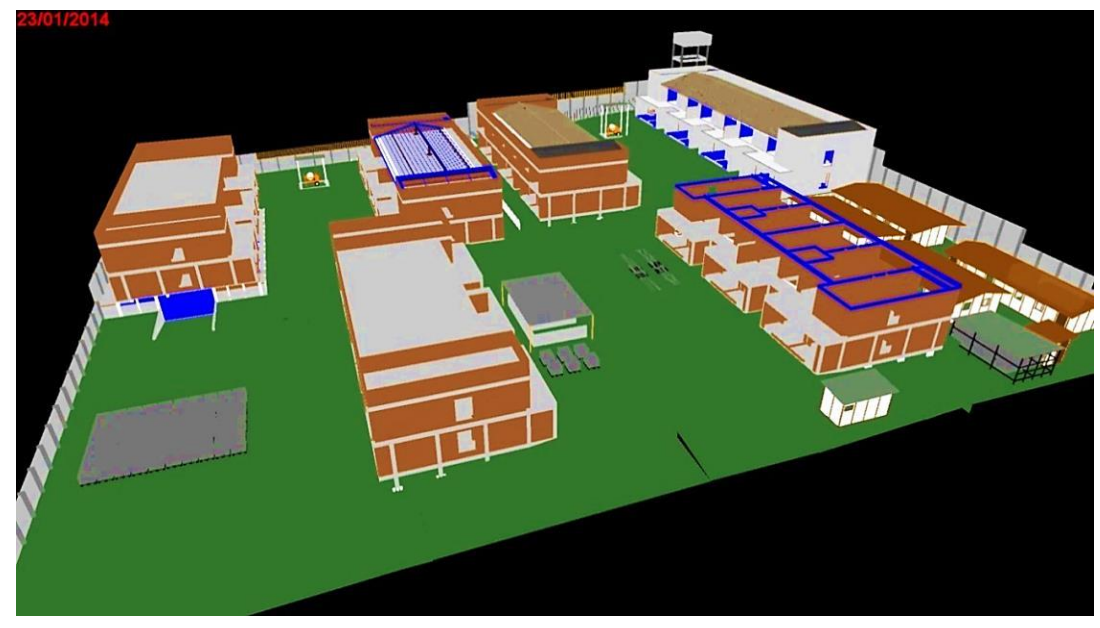

210 Brito, D. M. de; Ferreira, E. de A. M. 
A viabilização dessa nova estratégia para representação utilizando cores no modelo 4D adaptado exigiu uma alternativa flexível para atender aos requisitos e limitações. Para isso, faixas semitransparentes de pequena altura foram criadas próximo aos pavimentos de cada módulo, as quais apareceriam na simulação com a cor definida para cada atividade interna quando ela estivesse acontecendo. Visando facilitar a visualização e a identificação pelos usuários das cores escolhidas para as atividades internas, especialmente nos períodos em que a obra tinha muitas atividades acontecendo simultaneamente, em vários locais, foi decidido exibir uma legenda de representação durante a simulação, conforme a Figura 3, a qual diferencia as atividades internas por meio de legenda com cores específicas e representa as demais atividades em azul.

\section{Estratégias para análise e monitoramento do avanço físico}

O acompanhamento da execução da obra durante o estudo de caso se baseou no monitoramento do avanço físico por meio do modelo 4D como ferramenta de controle para os gestores detectarem discrepâncias entre os cronogramas Planejado e Realizado, tomando ações corretivas em tempo hábil. Para isso, a representação das discrepâncias entre os cronogramas exibidos na mesma simulação ocorre por diferenciação de cores para os estados das atividades, o qual segue outra escala de cores: verde - atividades adiantadas, azul atividades conforme o planejado, e vermelho atividades atrasadas. A Figura 4 apresenta a simulação em determinada data, seguindo a nova escala que define os estados das atividades.

Figura 3 - Uso de cores para diferenciação das atividades internas

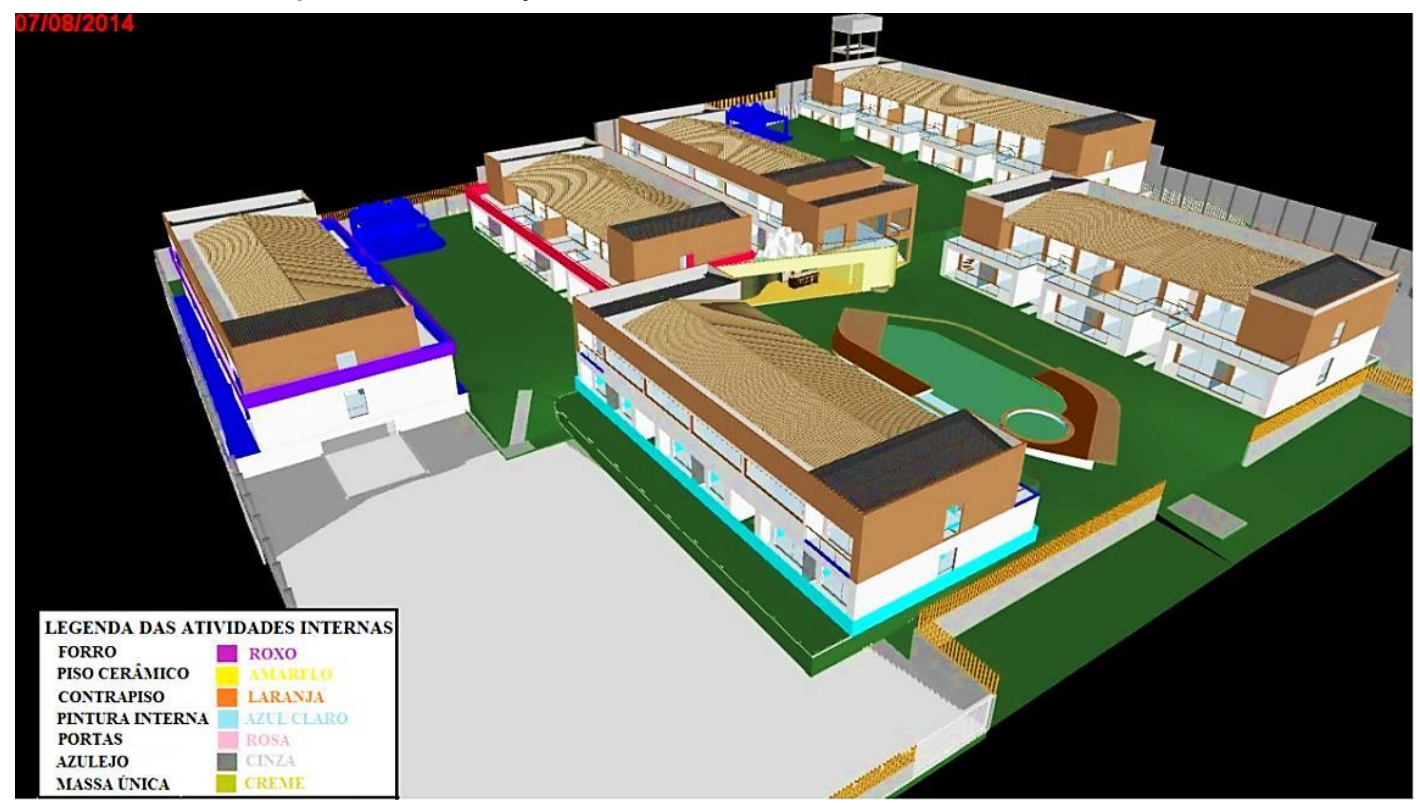

Figura 4 - Simulação dos cronogramas Planejado e Realizado com diferenciação de cores

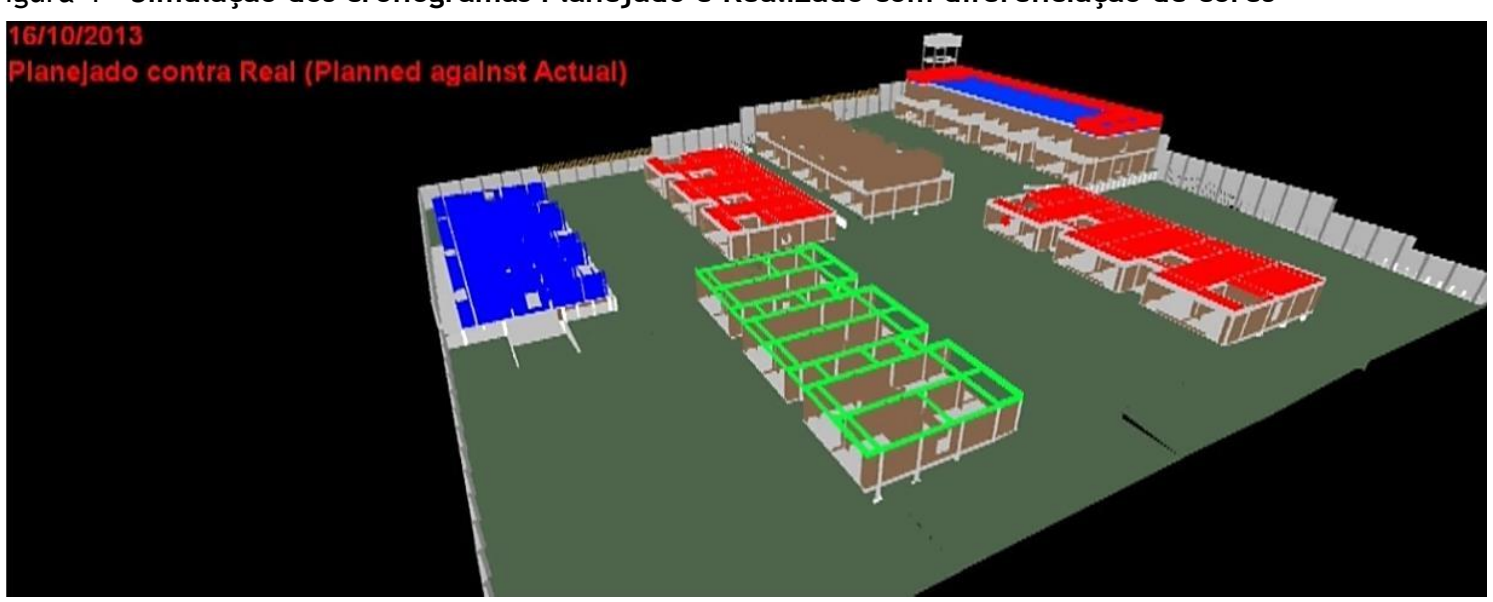


De acordo com Chang, Kang e Chen (2009), cores quentes, como é o caso do vermelho, são ideais para condições de atraso por atraírem a atenção dos espectadores para condições críticas. Entretanto, essa alternativa de monitoramento, mesmo com ajustes na velocidade da simulação, gerou algumas dificuldades aos usuários na análise de muitas atividades que ocorriam ao mesmo tempo em uma mesma tela.

Buscando melhores resultados com outra estratégia para análise e monitoramento, optou-se por adaptar o modelo BIM 4D para exibição dos cronogramas Planejado e Realizado lado a lado em tela dividida. A nova alternativa possibilitou o acompanhamento do avanço físico em datas específicas, com maior tempo de análise e precisão para identificação das discrepâncias, conforme pode ser visto na Figura 5 .

\section{Potencialidades da modelagem BIM 4D}

Após o desenvolvimento do modelo BIM 4D e sua aplicação ao planejamento e controle da obra, além das estratégias para representação e análise desenvolvidas, foram identificadas algumas potencialidades a partir da revisão da literatura e da observação dos pesquisadores e dos engenheiros responsáveis pelo empreendimento, conforme relação a seguir:

(a) redução do esforço na visualização e interpretação mental do planejamento;

(b) identificação de possíveis conflitos e interferências de espaço e tempo durante a construção; (c) inserção de equipamentos, elementos de canteiro e recursos para análises do planejamento;

(d) apoio no sequenciamento e na conformação ideal do ritmo de trabalho do cronograma;

(e) transmissão de possíveis impactos causados por mudanças no planejamento; e

(f) integração e comunicação entre todos os envolvidos no projeto.

\section{Análise e discussão dos resultados}

As estratégias e potencialidades, oriundas do estudo de caso, foram avaliadas, e o perfil dos participantes (sexo, formação profissional, grau acadêmico e nível de conhecimento e uso do BIM) é mostrado na Figura 6.

\section{Avaliação das potencialidades da modelagem BIM 4D}

Seis potencialidades foram avaliadas pelos profissionais da indústria da construção civil brasileira, que são analisadas a seguir com base no IC (95\%).

Em relação aos maiores graus de importância, foram observadas a identificação de possíveis conflitos e interferências de espaço e tempo durante a construção $(4,25 ; 4,53)$ e a integração e comunicação entre todos os envolvidos no projeto $(4,16 ; 4,56)$, como pode ser observado na Tabela 1 , a qual apresenta o ranking do grau de importância das potencialidades utilizando o IIR e a média de cada uma delas, além de permitir a visualização da frequência de respostas dos participantes.

Figura 5 - Visualização dos cronogramas Planejado e Realizado em tela dividida em data específica
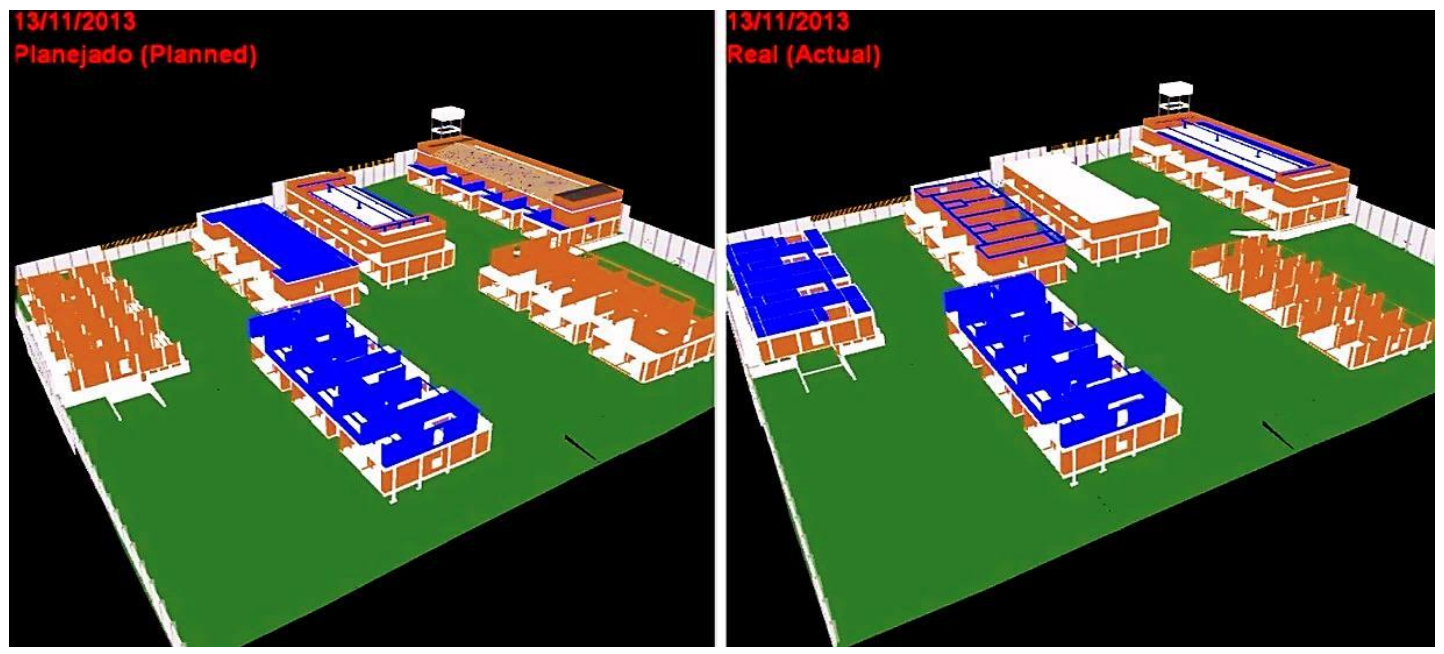

212 Brito, D. M. de; Ferreira, E. de A. M. 
Figura 6 - Perfil dos profissionais da construção civil brasileira que participaram da pesquisa
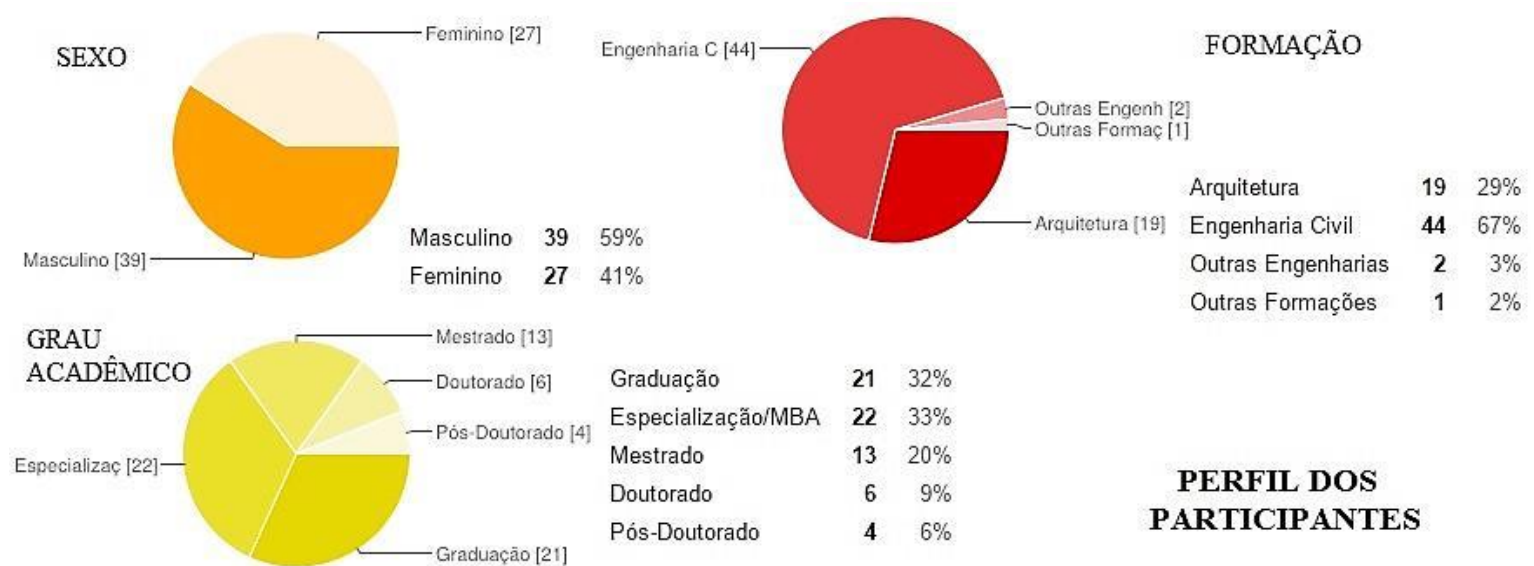

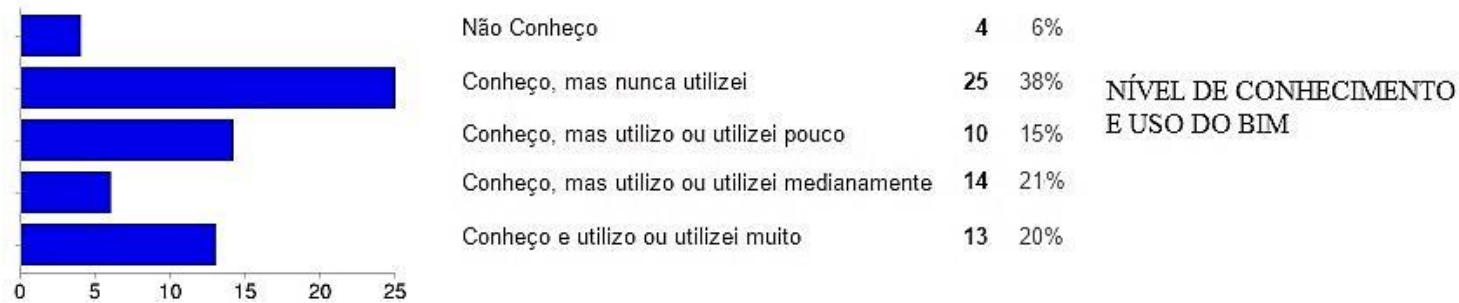

Tabela 1 - Ranking do grau de importância das potencialidades da modelagem BIM 4D

\begin{tabular}{|c|c|c|c|c|c|c|c|c|c|c|c|}
\hline Grau de Importância das Potencialidades da Modelagem 4D & 5 & 4 & 3 & 2 & 1 & $\mathrm{~N}$ & $\sum \mathrm{P}$ & IIR & Média & Desvpad & Rank \\
\hline Identificação de conflitos de espaço e tempo & 30 & 32 & 4 & 0 & 0 & 66 & 290 & 0,879 & 4,39 & 0,60 & 1 \\
\hline Integração e comunicação entre todos os envolvidos no projeto & 36 & 20 & 8 & 2 & 0 & 66 & 288 & 0,873 & 4,36 & 0,82 & 2 \\
\hline Redução do esforço na visualização e interpretação mental & 19 & 39 & 8 & 0 & 0 & 66 & 275 & 0,833 & 4,17 & 0,62 & 3 \\
\hline Transmissão de impactos devido a mudanças no planejamento & 22 & 33 & 11 & 0 & 0 & 66 & 275 & 0,833 & 4,17 & 0,69 & 3 \\
\hline Apoio no sequenciamento e conformação ideal do cronograma & 23 & 33 & 7 & 3 & 0 & 66 & 274 & 0,830 & 4,15 & 0,79 & 5 \\
\hline Inserção de equipamentos, elementos de canteiro e recursos & 16 & 43 & 7 & 0 & 0 & 66 & 273 & 0,827 & 4,14 & 0,58 & 6 \\
\hline
\end{tabular}

Com relação à aplicabilidade, as que obtiveram os maiores índices foram a identificação de possíveis conflitos e interferências de espaço e tempo durante a construção $(3,96 ; 4,34)$, a redução do esforço na visualização e interpretação mental do planejamento $(3,85 ; 4,19)$ e a integração e comunicação entre todos os envolvidos no projeto $(3,75 ; 4,21)$, conforme a Tabela 2 , a qual mostra o ranking para a aplicabilidade das potencialidades.

A análise das variáveis consideradas na pesquisa não identificou correlação significativa entre as potencialidades e estratégias, sendo constatadas apenas correlações de nível moderado positivo, de acordo com o coeficiente de Pearson, entre o grau de importância e a aplicabilidade das próprias potencialidades: apoio no sequenciamento e na conformação ideal do ritmo de trabalho do cronograma $(0,66)$ e transmissão de possíveis impactos causados por mudanças no planejamento $(0,62)$.
Com relação às correlações entre diferentes potencialidades, destacam-se as mais significativas de nível moderado positivo entre as aplicabilidades da identificação de possíveis conflitos e interferências de espaço e tempo durante a construção e da inserção de equipamentos, elementos de canteiro e recursos para análises do planejamento $(0,58)$ e as aplicabilidades da redução do esforço na visualização e interpretação mental do planejamento e da identificação de possíveis conflitos e interferências de espaço e tempo durante a construção $(0,56)$.

Entre os comentários dos participantes destacamse os seguintes: a redução do esforço na visualização e interpretação mental do planejamento é mais importante para aqueles que não dominam a parte técnica, mas tomam decisões administrativas; a identificação de possíveis conflitos e interferências de espaço e tempo durante a construção requer experiência específica, 
e avisos de conflitos em determinadas situações podem facilitar essa detecção; ferramentas como a linha de balanço podem permitir o apoio no sequenciamento e na conformação ideal do ritmo de trabalho do cronograma de maneira mais compreensível (o que pode explicar a avaliação dessa potencialidade como sendo a menos aplicável entre todas de acordo com a amostra geral).

Também foram analisados os maiores e menores graus de importância e aplicabilidade das potencialidades de acordo com a visão dos subgrupos, os quais são divididos ou combinados de acordo com especificidades relacionadas ao nível de conhecimento e utilização do BIM, a formação profissional, a área de atuação, o grau acadêmico, entre outras.

As Tabelas 3 e 4 mostram respectivamente os maiores e os menores graus de importância e aplicabilidade para cada potencialidade avaliada, indicando o IIR, a média, o desvio padrão e qual subgrupo obteve esses valores.
A análise da avaliação das potencialidades por subgrupos reforça os comentários destacados anteriormente. Os profissionais de projeto que não conhecem o BIM ou conhecem e nunca utilizaram, os quais costumam ter menos familiaridade com o cronograma da obra, foram os que consideraram a redução do esforço na visualização e interpretação mental do planejamento com o maior grau de importância entre os subgrupos. Os arquitetos com mestrado, doutorado ou pós-doutorado foram o subgrupo que considerou a identificação de possíveis conflitos e interferências de espaço e tempo com o maior grau de importância e aplicabilidade, reconhecendo a relevância da detecção de interferências em fases anteriores à construção. $\mathrm{O}$ apoio no sequenciamento e na conformação ideal do ritmo de trabalho do cronograma obteve o menor grau de importância e menor aplicabilidade entre os profissionais de gerenciamento com mestrado, doutorado ou pósdoutorado, indicando a possibilidade de eles estarem utilizando outras ferramentas para isso.

\section{Tabela 2 - Ranking da aplicabilidade das potencialidades da modelagem BIM 4D}

\begin{tabular}{|l|c|c|c|c|c|c|c|c|c|c|c|}
\hline Aplicabilidade das Potencialidades da Modelagem 4D & 5 & 4 & 3 & 2 & 1 & $\mathrm{~N}$ & $\sum \mathrm{P}$ & IIR & Média & Desvpad & Rank \\
\hline Identificação de conflitos de espaço e tempo & 22 & 35 & 6 & 3 & 0 & 66 & 274 & 0,830 & 4,15 & 0,77 & 1 \\
\hline Redução do esforço na visualização e interpretação mental & 16 & 36 & 13 & 1 & 0 & 66 & 265 & 0,803 & 4,02 & 0,71 & 2 \\
\hline Integração e comunicação entre todos os envolvidos no projeto & 25 & 20 & 16 & 5 & 0 & 66 & 263 & 0,797 & 3,98 & 0,97 & 3 \\
\hline Inserção de equipamentos, elementos de canteiro e recursos & 13 & 37 & 13 & 3 & 0 & 66 & 258 & 0,782 & 3,91 & 0,76 & 3 \\
\hline Transmissão de impactos devido a mudanças no planejamento & 11 & 39 & 13 & 3 & 0 & 66 & 256 & 0,776 & 3,88 & 0,73 & 5 \\
\hline Apoio no sequenciamento e conformação ideal do cronograma & 14 & 32 & 16 & 3 & 1 & 66 & 253 & 0,767 & 3,83 & 0,87 & 6 \\
\hline
\end{tabular}

Tabela 3 - Maiores graus de importância e aplicabilidade das potencialidades por subgrupos

\begin{tabular}{|c|c|c|c|c|c|c|c|c|}
\hline \multirow{2}{*}{ Potencialidades } & \multicolumn{3}{|c|}{$\begin{array}{l}\text { Maior Grau de } \\
\text { Importância }\end{array}$} & \multirow{2}{*}{ Amostra } & \multicolumn{3}{|c|}{ Maior Aplicabilidade } & \multirow{2}{*}{ Amostra } \\
\hline & IIR & Média & $\overline{\text { Desvpad }}$ & & IIR & Média & Desvpad & \\
\hline $\begin{array}{l}\text { Redução do esforço na visualização e } \\
\text { interpretação mental }\end{array}$ & 0,92 & 4,60 & 0,55 & $\begin{array}{c}5 \text { (Projeto e não } \\
\text { conhece o BIM } \\
\text { ou conhece e } \\
\text { nunca utilizou) }\end{array}$ & 0,89 & 4,44 & 0,53 & $\begin{array}{l}9 \text { (Projeto com } \\
\text { pós-graduação, } \\
\text { mestrado, } \\
\text { doutorado ou pós- } \\
\text { doutorado) }\end{array}$ \\
\hline $\begin{array}{c}\text { Identificação de conflitos de espaço } \\
\text { e tempo }\end{array}$ & 0,97 & 4,83 & 0,41 & $\begin{array}{l}6 \text { (Arquiteto com } \\
\text { mestrado, } \\
\text { doutorado ou pós- } \\
\text { doutorado) }\end{array}$ & 0,93 & 4,67 & 0,52 & $\begin{array}{c}6 \text { (Arquiteto } \\
\text { com mestrado, } \\
\text { doutorado ou pós- } \\
\text { doutorado) }\end{array}$ \\
\hline $\begin{array}{l}\text { Inserção de equipamentos, elementos } \\
\text { de canteiro e recursos }\end{array}$ & 0,93 & 4,67 & 0,52 & $\begin{array}{c}6 \text { (Arquiteto com } \\
\text { mestrado, } \\
\text { doutorado ou pós } \\
\text { doutorado) }\end{array}$ & 0,87 & 4,33 & 0,52 & $\begin{array}{c}6 \text { (Arquiteto } \\
\text { com mestrado, } \\
\text { doutorado ou pós- } \\
\text { doutorado) }\end{array}$ \\
\hline $\begin{array}{c}\text { Apoio no sequenciamento e } \\
\text { conformação ideal do cronograma }\end{array}$ & 0,93 & 4,63 & 0,52 & $\begin{array}{c}8 \text { (Pesquisa e } \\
\text { Ensino com } \\
\text { doutorado ou pós- } \\
\text { doutorado) }\end{array}$ & 0,88 & 4,38 & 0,52 & $\begin{array}{c}8 \text { (Pesquisa e } \\
\text { Ensino com } \\
\text { doutorado ou pós- } \\
\text { doutorado) }\end{array}$ \\
\hline $\begin{array}{l}\text { Transmissão de impactos devido a } \\
\text { mudanças no planejamento }\end{array}$ & 0,93 & 4,67 & 0,52 & $\begin{array}{l}6 \text { (Construção e } \\
\text { possui somente } \\
\text { graduação) }\end{array}$ & 0,84 & 4,22 & 0,44 & $\begin{array}{c}9 \text { (Projeto e } \\
\text { possui somente } \\
\text { graduação) }\end{array}$ \\
\hline $\begin{array}{l}\text { Integração e comunicação entre } \\
\text { todos os envolvidos no projeto }\end{array}$ & 0,96 & 4,80 & 0,45 & $\begin{array}{c}5 \text { (Projeto e não } \\
\text { conhece o BIM } \\
\text { ou conhece e } \\
\text { nunca utilizou) }\end{array}$ & 0,92 & 4,60 & 0,55 & $\begin{array}{c}\text { 5(Gerenciament } \\
\text { o com mestrado, } \\
\text { doutorado ou pós- } \\
\text { doutorado) }\end{array}$ \\
\hline
\end{tabular}

214 Brito, D. M. de; Ferreira, E. de A. M. 
Tabela 4 - Menores graus de importância e aplicabilidade das potencialidades por subgrupos

\begin{tabular}{|c|c|c|c|c|c|c|c|c|}
\hline \multirow[t]{2}{*}{ Potencialidades } & \multicolumn{3}{|c|}{$\begin{array}{c}\text { Menor Grau de } \\
\text { Importância }\end{array}$} & \multirow[t]{2}{*}{ Amostra } & \multicolumn{3}{|c|}{ Menor Aplicabilidade } & \multirow[t]{2}{*}{ Amostra } \\
\hline & IIR & Média & Desvpad & & IIR & Média & Desvpad & \\
\hline $\begin{array}{l}\text { Redução do esforço na visualização e } \\
\text { interpretação mental }\end{array}$ & 0,75 & 3,75 & 0,71 & $\begin{array}{c}8 \text { (Engenheiro } \\
\text { Civil com } \\
\text { mestrado, } \\
\text { doutorado ou pós- } \\
\text { doutorado) }\end{array}$ & 0,67 & 3,33 & 0,82 & $\begin{array}{l}6 \text { (Mestrado, } \\
\text { doutorado ou } \\
\text { pós-doutorado e } \\
\text { não conhece o } \\
\text { BIM ou conhece } \\
\text { e nunca utilizou) }\end{array}$ \\
\hline $\begin{array}{c}\text { Identificação de conflitos de espaço } \\
\text { e tempo }\end{array}$ & 0,82 & 4,09 & 0,54 & $\begin{array}{c}11 \\
\text { (Gerenciamento) }\end{array}$ & 0,73 & 3,67 & 1,21 & $\begin{array}{l}6 \text { (Construção e } \\
\text { possui somente } \\
\text { graduação) }\end{array}$ \\
\hline $\begin{array}{c}\text { Inserção de equipamentos, elementos } \\
\text { de canteiro e recursos }\end{array}$ & 0,77 & 3,83 & 0,41 & $\begin{array}{l}6 \text { (Construção e } \\
\text { possui somente } \\
\text { graduação) }\end{array}$ & 0,70 & 3,50 & 1,07 & $\begin{array}{l}8 \text { (Engenheiro } \\
\text { Civil, conhece e } \\
\text { utiliza ou } \\
\text { utilizou o BIM } \\
\text { pouco, } \\
\text { medianamente } \\
\text { ou muito) }\end{array}$ \\
\hline $\begin{array}{l}\text { Apoio no sequenciamento e } \\
\text { conformação ideal do cronograma }\end{array}$ & 0,68 & 3,40 & 1,52 & $\begin{array}{l}\text { 5(Gerenciamento } \\
\text { com mestrado, } \\
\text { doutorado ou pós- } \\
\text { doutorado) }\end{array}$ & 0,56 & 2,80 & 1,48 & $\begin{array}{l}\text { 5(Gerenciament } \\
\text { o com mestrado, } \\
\text { doutorado ou } \\
\text { pós-doutorado) }\end{array}$ \\
\hline $\begin{array}{l}\text { Transmissão de impactos devido a } \\
\text { mudanças no planejamento }\end{array}$ & 0,71 & 3,57 & 0,53 & $\begin{array}{c}\text { 7(Gerenciamento, } \\
\text { conhece e utiliza } \\
\text { ou utilizou o BIM } \\
\text { pouco, } \\
\text { medianamente ou } \\
\text { muito) }\end{array}$ & 0,67 & 3,33 & 0,82 & $\begin{array}{l}6 \text { (Mestrado, } \\
\text { dout orado ou } \\
\text { pós-doutorado e } \\
\text { não conhece o } \\
\text { BIM ou conhece } \\
\text { e nunca utilizou) }\end{array}$ \\
\hline $\begin{array}{l}\text { Integração e comunicação entre } \\
\text { todos os envolvidos no projeto }\end{array}$ & 0,80 & 4,00 & 0,89 & $\begin{array}{l}6 \text { (Mestrado, } \\
\text { doutorado ou pós- } \\
\text { doutorado e não } \\
\text { conhece o BIM } \\
\text { ou conhece e } \\
\text { nunca utilizou) }\end{array}$ & 0,60 & 3,00 & 0,63 & $\begin{array}{l}6 \text { (Mestrado, } \\
\text { doutorado ou } \\
\text { pós doutorado e } \\
\text { não conhece o } \\
\text { BIM ou conhece } \\
\text { e nunca utilizou) } \\
\end{array}$ \\
\hline
\end{tabular}

\section{Avaliação das estratégias para representação utilizando cores}

A avaliação dos participantes confirmou a tendência percebida durante o estudo de caso de que a representação utilizando cores para diferenciação das atividades internas do modelo facilita a visualização e o entendimento dos usuários. Para um IC de 95\%, a simulação do modelo BIM 4D com diferenciação de cores para as atividades internas obteve alto grau de importância $(3,92 ; 4,26)$ e aplicabilidade $(3,68$; $4,04)$ pela amostra geral, enquanto a representação das atividades externas e internas por cor única obteve médio grau de importância $(2,86 ; 3,32)$ e aplicabilidade $(2,83 ; 3,27)$. A frequência de respostas por grau de importância e aplicabilidade para essa avaliação pode ser vista na Figura 7.

A estratégia de representação com diferenciação de cores para as atividades internas obteve maiores médias em todos os subgrupos analisados, indicando sua aceitação em todas as estratificações da amostra, tendo atingido os graus de importância e aplicabilidade mais elevados no subgrupo formado por profissionais de pesquisa e ensino, que conheciam e utilizavam o BIM. A avaliação comparativa das duas estratégias para a amostra geral e os subgrupos pesquisados está na Tabela 5 , e a Figura 8 representa, por meio do gráfico radar, esse comparativo entre as 15 amostras enumeradas na tabela, demonstrando a uniformidade na avaliação dessa estratégia como a mais importante e aplicável.

Com relação às correlações entre o grau de importância e a aplicabilidade de cada uma das estratégias, a estratégia de diferenciação de cores para as atividades internas obteve um coeficiente de correlação de Pearson maior $(0,80)$, de nível forte positivo, em comparação com a representação de atividades internas e externas por cor única $(0,71)$, a qual obteve uma correlação de nível moderado positivo. Esses resultados de correlação positiva indicam tendência dos participantes em considerar as estratégias analisadas com graus de importância e aplicabilidade relacionados. 
Figura 7 - Frequência de respostas para as estratégias para representação utilizando cores

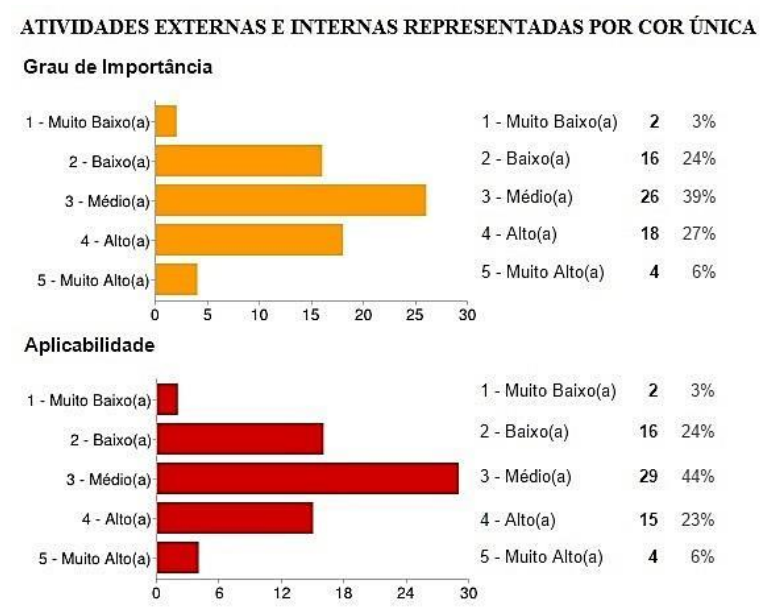

DIFERENCIAC̣̃̃O DE CORES PARA AS ATIVIDADES INTERNAS Grau de Importância

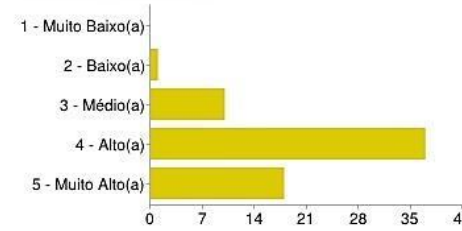

Aplicabilidade

1 - Muito Baixo(a).

2 - Baixo(a)

3 - Médio(a) -

4- Alto(a)

5 - Muito Alto(a)

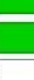

1 - Muito Baixo(a) $\quad 0 \quad 0 \%$

2-Baixo(a) $12 \%$

3 -Médio(a) $\quad 10 \quad 15 \%$

4 - Alto(a) $\quad 37 \quad 56 \%$

5 - Muito Alto(a) $\quad 18 \quad 27 \%$

Tabela 5 - Avaliação das estratégias para representação utilizando cores por subgrupos

\begin{tabular}{|c|c|c|c|c|c|c|c|c|c|}
\hline \multirow{2}{*}{$\begin{array}{l}\text { Legenda } \\
\text { para } \\
\text { Gráfico } \\
\text { Radar }\end{array}$} & \multirow{2}{*}{ Amostra } & \multicolumn{4}{|c|}{$\begin{array}{l}\text { Atividades externas e internas } \\
\text { representadas por cor única }\end{array}$} & \multicolumn{4}{|c|}{$\begin{array}{c}\text { Diferenciação de cores para as } \\
\text { atividades internas }\end{array}$} \\
\hline & & \multicolumn{2}{|c|}{ Grau de Importância } & \multicolumn{2}{|c|}{ Aplicabilidade } & \multicolumn{2}{|c|}{ Grau de Importância } & \multicolumn{2}{|c|}{ Aplicabilidade } \\
\hline 1 & 66 (Geral) & 3,09 & 0,94 & 3,05 & 0,92 & 4,09 & 0,70 & 3,86 & 0,74 \\
\hline 2 & $\begin{array}{l}39 \text { (Não Conhece o BIM ou conhece e nunca } \\
\text { utilizou ou conhece e utilizou ou utiliza pouco) }\end{array}$ & 3,15 & 0,96 & 2,97 & 0,96 & 4,10 & 0,68 & 3,82 & 0,76 \\
\hline 4 & 19 (Construção) & 3,26 & 1,10 & 3,05 & 0,85 & 4,05 & 0,71 & 3,68 & 0,67 \\
\hline 5 & 18 (Projeto) & 2,94 & 0,87 & 3,00 & 0,84 & 4,11 & 0,58 & 4,11 & 0,58 \\
\hline 6 & 11 (Gerenciamento) & 3,09 & 0,94 & 3,36 & 1,03 & 4,09 & 0,94 & 4,00 & 0,89 \\
\hline 10 & 43 (Graduação ou pós graduação) & 3,14 & 1,04 & 3,07 & 0,96 & 4,14 & 0,64 & 3,88 & 0,70 \\
\hline 11 & 23(Mestrado, doutorado ou pós-doutorado) & 3,00 & 0,74 & 3,00 & 0,85 & 4,00 & 0,80 & 3,83 & 0,83 \\
\hline 12 & $\begin{array}{l}4 \text { (Pesquisa e Ensino e não conhece o BIM ou } \\
\text { conhece e nunca utilizou) }\end{array}$ & 3,25 & 0,50 & 2,75 & 0,96 & 4,00 & 0,00 & 3,75 & 0,50 \\
\hline 13 & $\begin{array}{l}7 \text { (Pesquisa e Ensino, conhece o BIM e } \\
\text { utilizou ou utiliza pouco, med. ou muito) }\end{array}$ & 3,29 & 0,76 & 3,14 & 0,69 & 4,57 & 0,53 & 4,14 & 0,69 \\
\hline 14 & $\begin{array}{c}24 \text { (Engenheiros Civis e não conhecem o BIM } \\
\text { ou conhecem e nunca utilizaram) }\end{array}$ & 3,08 & 1,10 & 2,83 & 1,09 & 4,00 & 0,66 & 3,67 & 0,82 \\
\hline 15 & $\begin{array}{l}\text { 20(Engenheiros Civis, conhecem o BIM e } \\
\text { utilizaram ou utilizam pouco, med. ou muito) }\end{array}$ & 3,10 & 0,97 & 3,20 & 0,83 & 4,20 & 0,83 & 3,85 & 0,75 \\
\hline
\end{tabular}

216 Brito, D. M. de; Ferreira, E. de A. M. 
Figura 8 - Comparativo das estratégias para representação utilizando cores por subgrupos

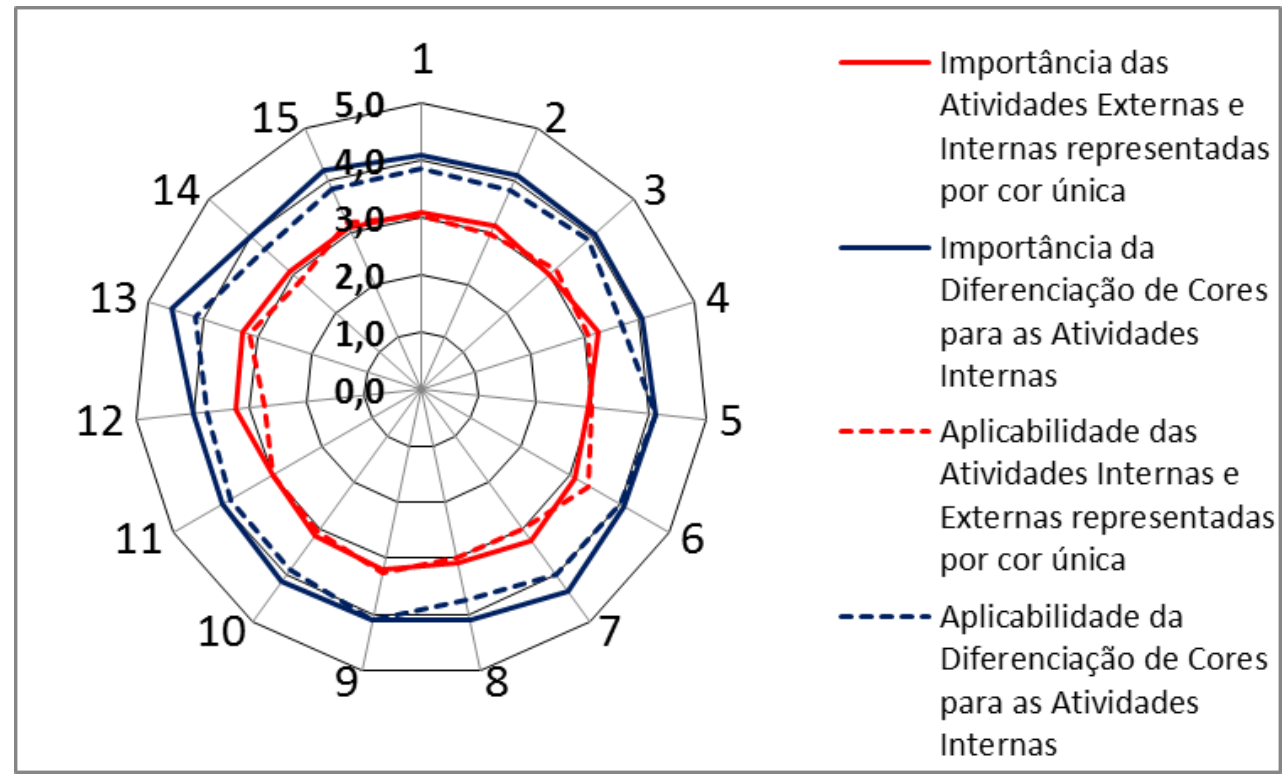

\section{Avaliação das estratégias para análise e monitoramento do avanço físico}

Entre as estratégias para análise e monitoramento do avanço físico utilizando modelos BIM 4D, com base em IC de 95\%, tanto a simulação dos cronogramas Planejado e Realizado com diferenciação de cores para os estados das atividades obteve alto grau de importância $(4,03$; $4,43)$ e aplicabilidade $(3,89 ; 4,29)$ quanto a visualização dos cronogramas Planejado e Realizado em tela dividida, em datas específicas, atingiu alto grau de importância $(4,00 ; 4,40)$ e aplicabilidade $(3,90 ; 4,32)$ na amostra geral dos profissionais da construção civil brasileira. A frequência de respostas para as duas estratégias avaliadas é apresentada na Figura 9, e a Tabela 6 retrata a avaliação comparativa das duas estratégias para a amostra geral e os subgrupos pesquisados.

Para os profissionais de gerenciamento, ambas as estratégias atingiram médias superiores à da amostra geral, destacando-se a boa avaliação da visualização dos cronogramas em tela dividida com médias de grau de importância e aplicabilidade elevadas. Já com relação aos profissionais de projeto e de pesquisa e ensino, a simulação dos cronogramas obteve médias de grau de importância e aplicabilidade maiores que a visualização em tela dividida.
Ambas as estratégias tiveram suas correlações entre o grau de importância e a aplicabilidade verificadas pelo coeficiente de correlação de Pearson. A estratégia de simulação dos cronogramas Planejado e Realizado com diferenciação de cores para os estados das atividades teve correlação de nível forte positivo $(0,84)$ assim como a visualização dos cronogramas Planejado e Realizado em tela dividida, em datas específicas, com correlação positiva de nível forte $(0,86)$, o que demonstra, mais uma vez, a tendência dos participantes de considerar as estratégias analisadas com graus de importância e aplicabilidade fortemente correlacionados.

\section{Avaliação da adoção da modelagem BIM 4D ao planejamento e controle de obras}

A última parte do questionário respondido pelos participantes consistiu em uma avaliação da adoção da modelagem BIM 4D ao planejamento e controle de obras. A Figura 10 apresenta a frequência de respostas do grau de importância e aplicabilidade dessa adoção e constata-se que nenhum participante considerou a adoção com grau de importância baixo, e 91\% avaliaram com grau alto ou muito alto. Quanto à aplicabilidade, $80 \%$ dos profissionais consideraram como alta ou muito alta. 
Figura 9 - Frequência de respostas sobre as estratégias para análise e monitoramento do avanço físico

SIMULACÃO DOS CRONOGRAMAS PLANEJADO X REALIZADO COM DIFERENCIAÇÃO DE CORES PARA OS ESTADOS DAS ATIVIDADES

\section{Grau de Importância}

1 - Muito Baixo(a)

2-Baixo(a) -

3 - Médio(a) -

4- Alto(a)

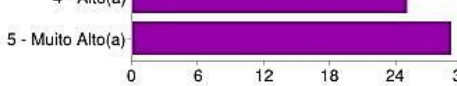

$\begin{array}{rlllll}0 & 6 & 12 & 18 & 24 & 30\end{array}$
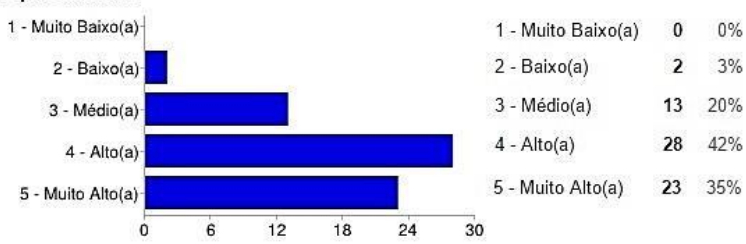

VISUALIZAC̃̃O DOS CRONOGRAMAS PLANEJADO X REALIZADO EM TELA DIVIDIDA EM DATAS ESPECIFICAS

Grau de Importância

1 - Muito Baixo(a)-

2-Baixo(a)

3 - Médio(a)

4 - Alto(a)

5 - Muito Alto(a)

$$
-
$$

Aplicabilidade

1 -Muito Baixo(a)-

2-Baixo(a)

3 - Médio(a)

4 - Alto(a)

5 - Muito Alto(a)

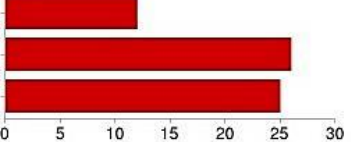

Tabela 6 - Avaliação das estratégias para análise e monitoramento do avanço físico por subgrupos

\begin{tabular}{|c|c|c|c|c|c|c|c|c|}
\hline \multirow[t]{3}{*}{ Amostra } & \multicolumn{4}{|c|}{$\begin{array}{c}\text { Simulação dos cronogramas Planejado } \\
\text { x Realizado com diferenciação de cores } \\
\text { para os estados das atividades }\end{array}$} & \multicolumn{4}{|c|}{$\begin{array}{c}\text { Visualização dos cronogramas } \\
\text { Planejado x Realizado em tela divida } \\
\text { em datas específicas }\end{array}$} \\
\hline & \multicolumn{2}{|c|}{ Grau de Importância } & \multicolumn{2}{|c|}{ Aplicabilidade } & \multicolumn{2}{|c|}{ Grau de Importância } & \multicolumn{2}{|c|}{ Aplicabilidade } \\
\hline & Média & Desvpad & Média & Desvpad & Média & Desvpad & Média & Desvpad \\
\hline 66 (Geral) & 4,23 & 0,82 & 4,09 & 0,82 & 4,20 & 0,83 & 4,11 & 0,86 \\
\hline $\begin{array}{l}39 \text { (Não Conhece o BIM ou conhece e } \\
\text { nunca utilizou ou conhece e utilizou ou } \\
\text { utiliza pouco) }\end{array}$ & 4,21 & 0,89 & 3,95 & 0,86 & 4,15 & 0,87 & 4,00 & 0,89 \\
\hline $\begin{array}{l}27 \text { (Conhece o BIM e utilizou ou utiliza } \\
\text { medianamente ou muito) }\end{array}$ & 4,26 & 0,71 & 4,30 & 0,72 & 4,26 & 0,76 & 4,26 & 0,81 \\
\hline 19 (Construção) & 4,26 & 0,81 & 4,05 & 0,85 & 4,53 & 0,70 & 4,42 & 0,77 \\
\hline 18 (Projeto) & 4,22 & 0,88 & 4,17 & 0,86 & 4,00 & 0,77 & 3,89 & 0,83 \\
\hline 11 (Gerenciamento) & 4,36 & 0,50 & 4,45 & 0,52 & 4,55 & 0,52 & 4,73 & 0,47 \\
\hline 43 (Possui graduação ou pós graduação) & 4,23 & 0,75 & 4,14 & 0,77 & 4,35 & 0,69 & 4,30 & 0,71 \\
\hline 23 (Possui mestrado, doutorado ou pós- & 4,22 & 0,95 & 4,00 & 0,90 & 3,91 & 1,00 & 3,74 & 1,01 \\
\hline $\begin{array}{c}8 \text { (Arquitetos e possuem somente } \\
\text { graduação) }\end{array}$ & 4,63 & 0,52 & 4,63 & 0,52 & 4,13 & 0,64 & 4,25 & 0,71 \\
\hline $\begin{array}{c}6 \text { (Construção e possui somente } \\
\text { graduação) }\end{array}$ & 4,33 & 0,82 & 4,00 & 0,89 & 4,83 & 0,41 & 4,67 & 0,52 \\
\hline $\begin{array}{l}6 \text { (Mestrado, doutorado ou pós-doutorado } \\
\text { e não conhece o BIM ou conhece e nunca } \\
\text { utilizou) }\end{array}$ & 3,83 & 1,47 & 3,33 & 1,21 & 3,67 & 1,37 & 3,17 & 1,17 \\
\hline
\end{tabular}

218 Brito, D. M. de; Ferreira, E. de A. M. 
Figura 10 - Frequência de respostas para adoção da Modelagem 4D ao planejamento e controle de obras Avaliação Geral para Adoção da Modelagem 4D

\section{Grau de Importância}

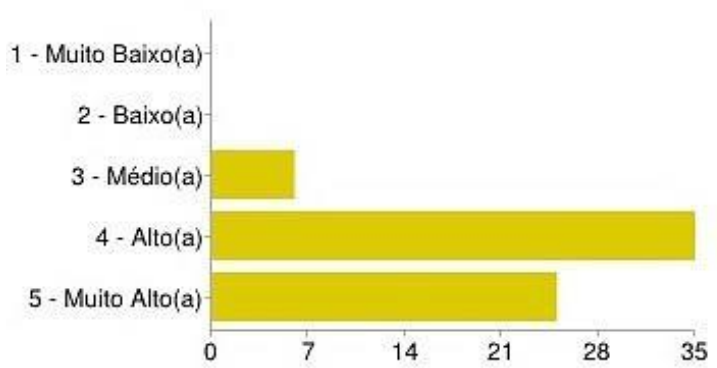

$\begin{array}{lrr}\text { 1-Muito Baixo(a) } & 0 & 0 \% \\ 2 \text { - Baixo(a) } & 0 & 0 \% \\ \text { 3-Médio(a) } & 6 & 9 \% \\ \text { 4-Alto(a) } & 35 & 53 \% \\ \text { 5-Muito Alto(a) } & 25 & 38 \%\end{array}$

Aplicabilidade

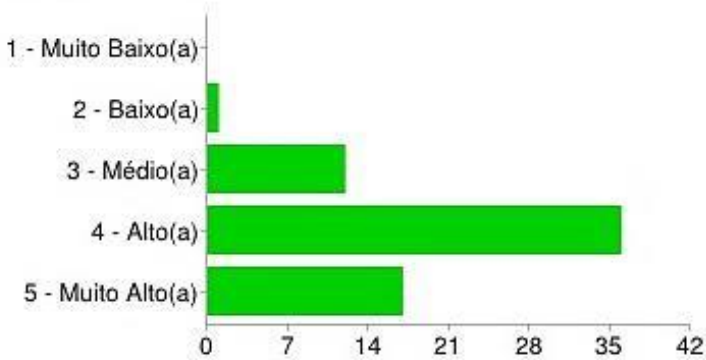

\begin{tabular}{lrr}
1 - Muito Baixo(a) & 0 & $0 \%$ \\
2 - Baixo(a) & 1 & $2 \%$ \\
3 - Médio(a) & 12 & $18 \%$ \\
4 - Alto(a) & 36 & $55 \%$ \\
\hline - Muito Alto(a) & 17 & $26 \%$
\end{tabular}

A Tabela 7 traz a média e o desvio padrão da amostra geral e dos subgrupos pesquisados sobre a adoção. Os profissionais da construção civil brasileira consideraram a adoção dos modelos BIM 4D ao planejamento e controle de obras, com base em IC de $95 \%$, com um alto grau de importância $(4,14 ; 4,44)$ e aplicabilidade $(3,88 ; 4,22)$.

Com relação aos subgrupos analisados, os resultados indicam que os profissionais com maior nível de conhecimento e utilização do BIM tendem a considerar a adoção mais importante e aplicável. Essa afirmação pode ser exemplificada comparando-se o grau de importância $(3,83)$ e aplicabilidade $(3,50)$ dos profissionais com mestrado, doutorado ou pós-doutorado que não conheciam ou nunca utilizaram o BIM, com as médias de importância $(4,53)$ e aplicabilidade $(4,53)$ dos participantes com esses mesmos níveis acadêmicos, mas que já conheciam o BIM e utilizavam ou utilizam suas aplicações na construção civil.

Os maiores graus de importância da adoção por áreas de atuação profissional foram pesquisa e ensino $(4,45)$, projeto $(4,39)$ e gerenciamento $(4,36)$, enquanto na construção obteve a menor média (4,21). Apenas entre os profissionais de gerenciamento, a aplicabilidade superou o grau de importância, atingindo a maior média $(4,45)$, seguida pelas áreas de pesquisa e ensino $(4,27)$, projeto $(4,17)$ e construção $(3,74)$, muito possivelmente indicando maior familiaridade dos primeiros com as aplicações dos modelos BIM 4D ao planejamento e controle e maior ceticismo na área de construção.

A correlação entre o grau de importância e a aplicabilidade também foi verificada para a adoção da modelagem 4D, tendo sido detectada uma correlação de nível moderado positivo $(0,56)$, o que demonstra tendência dos participantes em considerarem a adoção com graus de importância e aplicabilidade moderadamente correlacionados.

\section{Conclusões}

Este trabalho teve como objetivo avaliar estratégias para representação e análise do planejamento e controle de obras utilizando modelos BIM 4D segundo a visão da indústria da construção civil brasileira. A pesquisa foi realizada utilizando um questionário digital, que foi respondido por 66 profissionais de várias áreas do setor. 
Tabela 7 - Avaliação da adoção da modelagem 4D ao planejamento e controle de obras por subgrupos

\begin{tabular}{|c|c|c|c|c|}
\hline \multirow{3}{*}{ Amostra } & \multicolumn{4}{|c|}{$\begin{array}{c}\text { Adoção da Modelagem 4D ao Planejamento e } \\
\text { Controle de Obras } \\
\end{array}$} \\
\hline & \multicolumn{2}{|c|}{ Grau de Importância } & \multicolumn{2}{|c|}{ Aplicabilidade } \\
\hline & Média & Desvpad & Média & Desvpad \\
\hline 66 (Geral) & 4,29 & 0,63 & 4,05 & 0,71 \\
\hline $\begin{array}{c}39 \text { (Não Conhece o BIM ou conhece e nunca utilizou ou conhece e } \\
\text { utilizou ou utiliza pouco) }\end{array}$ & 4,21 & 0,66 & 3,95 & 0,65 \\
\hline 27 (Conhece o BIM e utilizou ou utiliza medianamente ou muito) & 4,41 & 0,57 & 4,19 & 0,79 \\
\hline 19 (Construção) & 4,21 & 0,63 & 3,74 & 0,73 \\
\hline 18 (Projeto) & 4,39 & 0,61 & 4,17 & 0,51 \\
\hline 11 (Gerenciamento) & 4,36 & 0,67 & 4,45 & 0,52 \\
\hline 11 (Pesquisa e Ensino & 4,45 & 0,52 & 4,27 & 0,65 \\
\hline 44 (Engenheiros Civis) & 4,25 & 0,65 & 4,00 & 0,75 \\
\hline 19 (Arquitetos) & 4,37 & 0,60 & 4,16 & 0,69 \\
\hline 43 (Possui graduação ou pós graduação) & 4,26 & 0,58 & 3,93 & 0,63 \\
\hline 23 (Possui mestrado, doutorado ou pós-doutorado) & 4,35 & 0,71 & 4,26 & 0,81 \\
\hline 6 (Arquitetos com mestrado, doutorado ou pós-doutorado) & 4,67 & 0,52 & 4,67 & 0,52 \\
\hline $\begin{array}{c}8 \text { (Construção, conhece o BIM e utilizou ou utiliza pouco, } \\
\text { medianamente ou muito) }\end{array}$ & 4,38 & 0,52 & 3,88 & 0,83 \\
\hline $\begin{array}{l}6 \text { (Mestrado, doutorado ou pós-doutorado e não conhece o BIM ou } \\
\text { conhece e nunca utilizou) }\end{array}$ & 3,83 & 0,75 & 3,50 & 0,84 \\
\hline $\begin{array}{c}17 \text { (Mestrado, doutorado ou pós-doutorado, conhece o BIM e utilizou } \\
\text { ou utiliza pouco, medianamente ou muito) }\end{array}$ & 4,53 & 0,62 & 4,53 & 0,62 \\
\hline
\end{tabular}

Seis potencialidades da modelagem BIM 4D foram avaliadas nesta pesquisa, sendo estabelecidos rankings do grau de importância e aplicabilidade a partir do cálculo do Índice de Importância Relativa (IIR) e da média de cada potencialidade. A identificação de possíveis conflitos e interferências de espaço e tempo durante a construção obteve os maiores índices. O segundo maior grau de importância foi associado à integração e comunicação entre todos os envolvidos no projeto, enquanto a redução do esforço na visualização e interpretação mental do planejamento foi considerada como a segunda maior aplicabilidade.

Entre as estratégias avaliadas para representação utilizando cores, a simulação com diferenciação de cores para as atividades internas superou os resultados da representação utilizando cor única na visão geral dos participantes e de todos os subgrupos analisados, demonstrando a aceitação dessa estratégia pelos usuários por facilitar a visualização interna e o entendimento do modelo. Além disso, foi percebido que os participantes com maiores familiaridades com o BIM e suas aplicações consideravam a estratégia de diferenciação de cores com maior importância e aplicabilidade em comparação aos que não conheciam ou nunca utilizaram o BIM.

Ambas as estratégias utilizadas para análise e monitoramento do avanço físico foram bem avaliadas pelos profissionais brasileiros. A estratégia de simulação dos cronogramas obteve melhor avaliação entre os profissionais das áreas de projeto e de pesquisa e ensino, enquanto os profissionais da construção e gerenciamento consideraram a visualização dos cronogramas em tela dividida com maiores graus de importância e aplicabilidade. Vale ressaltar o comentário de alguns participantes de que a simulação dos cronogramas Planejado e Realizado poderia ser útil para identificar discrepâncias menos perceptíveis; já a visualização deles em tela dividida teria maior utilidade para analisar desvios macro.

A pesquisa também avaliou a adoção da modelagem BIM 4D ao planejamento e controle de obras. As médias da amostra geral dos participantes para o grau de importância $(4,29)$ e aplicabilidade $(4,05)$ foram altas, indicando seu potencial estratégico para combater as dificuldades do gerenciamento baseado no uso não integrado e isolado das técnicas tradicionais. Entretanto, vários entraves à propagação foram lembrados pelos profissionais, tais como estágio tecnológico atual, cultura local, relação entre o nível de detalhamento do modelo e os benefícios gerados, necessidade de dar maior importância às análises de fluxo no canteiro, e não apenas às atividades de conversão, treinamento dos envolvidos, custo das ferramentas e falta de profissionais qualificados no mercado.

A análise dos dados do estudo demonstra não apenas os graus de importância e aplicabilidade dos aspectos avaliados de acordo com a visão geral da amostra, mas também segundo a ótica de 
subgrupos do setor, divididos ou combinados pelo nível de conhecimento e uso do BIM, formação profissional, área de atuação e grau acadêmico.

As principais limitações da pesquisa são resultantes do tamanho da amostra e da origem dos profissionais participantes, pois se trata de uma pesquisa realizada no setor da construção civil brasileira, com diversas variáveis particulares envolvidas, tais como características culturais e desenvolvimento tecnológico, mas que pode ser representativa para generalização em situações que guardem alguma similaridade. Ademais, a divisão da amostra em subgrupos relacionados com características específicas resulta em amostras menores com maiores limitações, o que pode acarretar eventuais desvios ou vieses no que está sendo medido.

Este trabalho apresenta contribuições referentes ao conhecimento da visão da indústria da construção civil brasileira sobre potencialidades, estratégias para representação e análise, e possibilidades de adoção dos modelos BIM 4D ao planejamento e controle de obras, fornecendo informações para uma melhor compreensão da percepção dos usuários e possibilitando uma melhor identificação de suas necessidades.

Os resultados da pesquisa indicam que a integração e comunicação entre os envolvidos no projeto e a redução do esforço na visualização e interpretação mental do planejamento estão entre os maiores potenciais da utilização dos modelos BIM 4D, demonstrando seu poder de integração e visualização, o que pode facilitar a compatibilização dos níveis de planejamento, referidos por Laufer e Tucker (1987), e o desenvolvimento de estratégias para produção adaptadas às particularidades do setor, citadas por Formoso e Ino (2003).

O estudo traz avanços para a resolução da dificuldade relacionada à visualização interna dos modelos BIM 4D ao apresentar a estratégia de diferenciação de cores para representação e visualização das atividades internas. Além disso, as estratégias para representação e análise avaliadas nesta pesquisa podem ser implementadas pelos usuários e incorporadas, de forma complementar, a metodologias de implantação do BIM para planejamento e controle da produção, e a diretrizes existentes para interação, visualização e representação.

Os pesquisadores recomendam que trabalhos futuros desenvolvam e avaliem outras estratégias para representação e análise do planejamento e controle de obras utilizando modelos BIM 4D, com maior nível de detalhe para análises de fluxos, automatização da visualização das atividades internas com utilização de cores, e representação simultânea dos cronogramas Planejado e Realizado em tela dividida no próprio software. Ademais, sugere-se que a avaliação dessas estratégias também seja realizada com profissionais da indústria da construção civil de outros países.

\section{Referências}

AMORIM, S. R. L. Relatório BIM: Building Information Modeling no Brasil. Projeto Apoio aos Diálogos Setoriais União Europeia - Brasil, 2014.

BERNSTEIN, H. M. et al. The Business Value of BIM for Construction in Major Global

Markets. Bedford: McGraw Hill Construction, 2014.

BIOTTO, C. N.; FORMOSO, C. T.; ISATTO, E. L. O Uso da Modelagem BIM 4D na Projeto e Gestão de Sistemas de Produção em Empreendimentos de Construção. In: ENCONTRO NACIONAL DE TECNOLOGIA DO AMBIENTE CONSTRUÍDO, 14., Juiz de Fora, 2012. Anais... Porto Alegre: ANTAC, 2012.

BIOTTO, C. N.; FORMOSO, C. T.; ISATTO, E. L. Método Para o Uso da Modelagem BIM 4D na Gestão da Produção em Empreendimentos de Construção. In: SIMPÓSIO BRASILEIRO DE QUALIDADE DO PROJETO NO AMBIENTE CONSTRUÍDO, 3.; ENCONTRO DE TECNOLOGIA DE INFORMAÇÃO E COMUNICAÇÃO NA CONSTRUÇÃO, 6 . Campinas, 2013. Anais... Porto Alegre: ANTAC, 2013.

BOTON, C.; HALIN, G.; KUBICKI, S. Characterizing Collaborative 4D Use Contexts to Improve Interaction Mechanisms Design. In: INTERNATIONAL CONFERENCE ON COMPUTING IN CIVIL AND BUILDING ENGINEERING, Orlando, 2014. Proceedings... Orlando, 2014.

CAO, D. et al. Practices and Effectiveness of Building Information Modelling in Construction Projects in China. Automation in Construction, v. 49, p. 113-122, 2015.

CASTRONOVO, F. et al. Visualization in 4D Construction Management Software: A Review of Standards and Guidelines. In: INTERNATIONAL CONFERENCE ON COMPUTING IN CIVIL AND BUILDING ENGINEERING, Orlando, 2014. Proceedings... Orlando, 2014.

CHANG, H. S.; KANG S. C.; CHEN, P. H. Systematic Procedure of Determining an Ideal Color Scheme on 4D Models. Advanced Engineering Informatics, v. 23, n. 4, p. 463-473, 2009. 
CHEN, Y. et al. Selection and Evaluation of Color Scheme for 4D Construction Models. Journal of Information Technology in Construction, v. 18, p. 1-19, 2013.

EADIE, R. et al. BIM Implementation Throughout the UK Construction Project Lifecycle: an analysis. Automation in Construction, v. 36, p. 145-151, 2013.

EASTMAN, C. et al. BIM Handbook: a guide to building information modeling for owners, managers, designers, engineers and contractors. $2^{\text {nd }}$ ed. New Jersey: John Wiley \& Sons, 2011.

FORMOSO, C. T.; INO, A. Inovação, Gestão da Qualidade e Produtividade e Disseminação do Conhecimento na Construção Habitacional. Porto Alegre: ANTAC, 2003. v. 2. Coletânea Habitare.

GOLPARVAR-FARD, M. et al. Visualization of Construction Progress Monitoring With 4D Simulation Model Overlaid on Time-Lapsed Photographs. Journal of Computing in Civil Engineering, v. 23, n. 6, p. 391-404, 2009.

HARTMANN, T.; GAO, J.; FISCHER, M. Areas of Application for 3D and 4D Models on Construction Projects. Journal of Construction Engineering and Management, v. 143, n. 10, p. 776-785, 2008.

HORA, H. R. M.; MONTEIRO, G. T. R.; ARICA, J. Confiabilidade em Questionários Para Qualidade: um estudo com o coeficiente alfa de cronbach. Produto \& Produção, v. 11, n. 2, p. 85103, 2010.

KASSEM, M. Strategy For the Diffusion of Building Information Modelling in Brazil: executive summary report. Projeto Apoio aos Diálogos Setoriais União Europeia - Brasil, 2014.

KOO, B.; FISCHER, M. Feasibility Study of 4D CAD in Commercial Construction. Journal of Construction Engineering and Management, v. 126, n. 4, p. 251-260, 2000.

LAUFER, A.; TUCKER, R. L. Is Construction Planning Really Doing Its Job? A critical examination of focus, role and process.

Construction Management and Economics, v. 5, n. 5, p. 243-266, 1987.

LEE, S.; YU, J.; JEONG, D. BIM Acceptance Model in Construction Organizations. Journal of Management in Engineering, 2013.

LI, H. et al. Virtual Prototyping For Planning Bridge Construction. Automation in Construction, v. 27, p. 1-10, 2012.
LIMMER, C. V. Planejamento, Orçamentação e Controle de Projetos e Obras. Rio de Janeiro: Livros Técnicos e Científicos Editora, 1997.

MAHALINGAM, A.; KASHYAP, R.;

MAHAJAN, C. An Evaluation of the Applicability of $4 \mathrm{D}$ CAD on Construction Projects. Automation in Construction, v. 19, n. 2, p. 148-159, 2010.

MATTOS, A. D. Planejamento e Controle de Obras. São Paulo: Editora Pini, 2010.

MOON, H.; DAWOOD, N., KANG, L. Development of Workspace Conflict Visualization System Using 4D Object of Work Schedule. Advanced Engineering Informatics, v. 28, p. 5065, 2014.

MUHWEZI, L.; ACAI, J.; OTIM, G. An

Assessment of the Factors Causing Delays on Building Construction Projects in Uganda.

International Journal of Construction Engineering and Management, v. 3, n. 1, p. 1323, 2014.

OLDE SCHOLTENHUIS, L.; HARTMANN, T.; DORÉE, A. Comparing Mindfulness in Manual and 4D-Supported Coordination Practices. In: CONSTRUCTION RESEARCH CONGRESS, Atlanta, 2014. Proceedings... Atlanta, 2014.

PARK, J. et al. 3D/4D CAD Applicability for Life-Cycle Facility Management. Journal of Computing in Civil Engineer, v.25, n. 2, p. 129138, 2011.

RUSSELL, A.; CHIU, C.; KORDE, T. Visual Representation of Construction Management Data. Automation in Construction, v. 18, n. 8, p. 1045 1062, dec. 2009.

RUSSELL, A. et al. Visualizing High-Rise Building Construction Strategies Using Linear Scheduling and 4D CAD. Automation in Construction, v. 18, n. 2, p. 219-236, 2009.

SCHEER, S. et al. On-Site BIM Model Use to Integrate 4D/5D Activities and Construction Works: A Case Study on a Brazilian Low Income Housing Enterprise. In: INTERNATIONAL CONFERENCE ON COMPUTING IN CIVIL AND BUILDING ENGINEERING, Orlando, 2014. Proceedings... Orlando, 2014.

SONG, S.; YANG, J.; KIM, N. Development of a BIM-Based Structural Framework Optimization and Simulation System for Building Construction. Computers in Industry, v. 63, p. 895-91, 2012.

SOUSA, N. M. Gestão de Projetos na

Construção: modelo de avaliação do desempenho em projetos. Lisboa. 2008. Dissertação (Mestrado em Engenharia Civil) - Instituto Superior Técnico, Lisboa, 2008. 
UNITED STATES NATIONAL BUILDING INFORMATION MODELING STANDARD, Overview, Principles, and Methodologies: version 1, part 1. National Institute of Building Sciences, 2008.

XU, H.; FENG J.; LI, S. Users-Orientated Evaluation of Building Information Model in the Chinese Construction Industry. Automation in Construction, v. 39, p. 32-46, 2014.

\section{Agradecimentos}

Agradecemos a todos os participantes desta pesquisa pelas suas respostas, comentários e sugestões, e às empresas que colaboraram com o nosso grupo de pesquisa, pela disponibilização de informações e apresentação de suas estratégias de representação, bem como pelo apoio no desenvolvimento do estudo de caso.

Douglas Malheiro de Brito

Diretoria de Obras | Companhia de Transportes da Bahia | Rua Baixa de Santo Antônio 01, Retiro | Salvador - BA - Brasil | CEP $41185-270$ | Tel.: (71) 3116-4993 | E-mail: douglas_ssa@hotmail.com

Emerson de Andrade Marques Ferreira

Departamento de Construção e Estruturas, Escola Politécnica | Universidade Federal da Bahia | Rua Aristides Novis 02, Federação | Salvador - BA - Brasil | CEP 40210-630 | Tel.: (71) 3283-9462 / 9725 | E-mail: emerson@ufba.br

\section{Revista Ambiente Construído}

Associação Nacional de Tecnologia do Ambiente Construído

Av. Osvaldo Aranha, $99-3^{\circ}$ andar, Centro

Porto Alegre - RS - Brasil

CEP $90035-190$

Telefone: +55 (51) 3308-4084

Fax: +55 (51) 3308-4054

www.seer.ufrgs.br/ambienteconstruido

E-mail: ambienteconstruido@ufrgs.br 